\title{
Composition Optimization, High-temperature Stability and Thermal Cycling Performance of Sc- doped Gd2Zr207 Thermal Barrier Coatings: Theoretical and Experimental Studies
}

\section{Lei Guo ( $\sim$ glei028@tju.edu.cn )}

Tianjin University

\section{Bowen Li}

Tianjin University

\section{Yuxian Cheng}

AECC Shengyang Liming Aero Engine Group Corporation Ltd.

\section{Lu Wang}

AECC Shenyang Liming Aero Engine Group Corporation Ltd.

\section{Research Article}

Keywords: Thermal barrier coatings, First-principles calculation, Solid solution mechanism, Hightemperature stability, Thermal cycling

Posted Date: August 31st, 2021

DOI: https://doi.org/10.21203/rs.3.rs-557940/v2

License: (c) (1) This work is licensed under a Creative Commons Attribution 4.0 International License.

Read Full License

Version of Record: A version of this preprint was published at Journal of Advanced Ceramics on January 19th, 2022. See the published version at https://doi.org/10.1007/s40145-021-0549-z. 


\section{Composition optimization, high-temperature stability and}

\section{thermal cycling performance of Sc-doped $\mathrm{Gd}_{2} \mathrm{Zr}_{2} \mathrm{O}_{7}$ thermal}

\section{barrier coatings: theoretical and experimental studies}

Lei Guo a,b*, Bowen $\mathrm{Li}^{\mathrm{a}}$, Yuxian Cheng ${ }^{\mathrm{c}}$, Lu Wang ${ }^{\mathrm{c}}$

${ }^{a}$ School of Materials Science and Engineering, Tianjin University, Tianjin, 300072, China

${ }^{\mathrm{b}}$ Tianjin Key Laboratory of Advanced Joining Technology, Key Lab of Advanced Ceramics and Machining Technology of Ministry of Education, Tianjin, 300072, China

c AECC Shenyang Liming Aero Engine Group Corporation Ltd., Shenyang 110043, China

\section{* Corresponding author:}

Lei Guo

Tel: +86 18322186422; E-mail address: glei028@ tju.edu.cn.

\section{Abstract}

Sc was doped into $\mathrm{Gd}_{2} \mathrm{Zr}_{2} \mathrm{O}_{7}$ for expanding the potential for thermal barrier coating (TBC) applications. According to first-principles calculation, solid solution mechanism of $\mathrm{Sc}$ in $\mathrm{Gd}_{2} \mathrm{Zr}_{2} \mathrm{O}_{7}$ lattice was revealed, i.e., Sc atoms first occupy the lattice interstitial sites followed by substituting for Gd, and the interstitial Sc concentration is less than 11.11 at. \%. By considering the mechanical and thermophysical properties comprehensively, the optimum Sc doping content was determined to be 16.67 at. $\%$, and this Sc content was selected to produce TBCs by air plasma spraying with YSZ as a bottom ceramic coating (Gd-Sc/YSZ TBC). After sintering at $1400{ }^{\circ} \mathrm{C}$ for $100 \mathrm{~h}, \mathrm{Gd}-$ Sc coatings retain phase and structural stability indicative of excellent sintering resistance. By thermal cycling tests, Gd-Sc TBCs fail due to the low toughness and the 
interface reaction between Gd-Sc and bond coat, while Gd-Sc/YSZ TBCs exhibit much longer thermal cycling lifetime, and the failure mode is YSZ coating cracking.

Keyword: Thermal barrier coatings; First-principles calculation; Solid solution mechanism; High-temperature stability; Thermal cycling.

\section{Introduction}

Thermal barrier coating (TBC) is a kind of high temperature protective coating used for aero turbine engine blades, prolonging blade working lifetime, improving thrust to weight ratio and thermal efficiency [1-3]. TBCs are generally composed of a ceramic topcoat, thermally grown oxide (TGO), bond coat and superalloy substrate. The ceramic topcoat generally has the properties of low thermal conductivity, high chemical stability and thermal expansion coefficient (TEC) to meet the requirements of reducing the surface temperature of the substrate and the thermal stress between the substrate and bond coat [4-5]. The traditional ceramic topcoat material is $\mathrm{Y}_{2} \mathrm{O}_{3}$ partially stabilized $\mathrm{ZrO}_{2}$ (YSZ), which has good thermal and mechanical properties [6-8]. However, a transition from metastable tetragonal phase $\left(\mathrm{t}^{\prime}\right)$ to monoclinic phase $(\mathrm{m})$ occurs when YSZ is in long-term service above $1200{ }^{\circ} \mathrm{C}$, which is often accompanied by volume expansion, resulting in coating spallation; in addition, YSZ has sintering shrinkage and other problems during long-term service, which greatly reduces the thermal insulation performance of the coating [4, 9-10]. 
In recent years, rare earth zirconates $\left(\mathrm{RE}_{2} \mathrm{Zr}_{2} \mathrm{O}_{7}, \mathrm{RE}=\right.$ rare earth element $)$ have been widely concerned by many scholars. Because of their low thermal conductivity, high TEC and good phase stability, they are a series of good candidates for TBC applications. Among the rare earth zirconates, $\mathrm{Gd}_{2} \mathrm{Zr}_{2} \mathrm{O}_{7}$ has the lowest thermal conductivity and highest TEC, so it is regarded as one of the most promising thermal barrier coating materials [11-12]. In addition, $\mathrm{Gd}_{2} \mathrm{Zr}_{2} \mathrm{O}_{7}$ has low oxygen permeability and structural stability at higher temperature [13]. However, the mechanical properties of $\mathrm{Gd}_{2} \mathrm{Zr}_{2} \mathrm{O}_{7}$ are poor, which limits its application.

$\mathrm{Gd}_{2} \mathrm{Zr}_{2} \mathrm{O}_{7}$ has two crystal structures, namely pyrochlore structure and defect fluorite structure, both of which are face centered cubic space lattice [14-15]. $\mathrm{Gd}^{3+}$ and $\mathrm{Zr}^{4+}$ lattice sites can be replaced by other ions, and some small ions could also enter the interstitial sites. Therefore, the thermal conductivity of $\mathrm{Gd}_{2} \mathrm{Zr}_{2} \mathrm{O}_{7}$ can be further reduced by selectively doping other ions in a single $\mathrm{Gd}_{2} \mathrm{Zr}_{2} \mathrm{O}_{7}$, which makes it possible to improve its thermophysical properties and mechanical properties. It is reported that the TEC of $\mathrm{RE}_{2} \mathrm{Zr}_{2} \mathrm{O}_{7}$ increases with the decrease of $\mathrm{RE}^{3+}$ (rare earth) size [16]. Zhang et al. [11] found that the fracture toughness of $\mathrm{Gd}_{2} \mathrm{Zr}_{2} \mathrm{O}_{7}$ can be increased by doping $\mathrm{Yb}^{3+}$. Lee et al. [17] found that the doping $\mathrm{Y}^{3+}$ can significantly improve mechanical properties and insulation performance in $\mathrm{Gd}_{2} \mathrm{Zr}_{2} \mathrm{O}_{7}$. These results show that doping small $\mathrm{RE}^{3+}$ in $\mathrm{Gd}_{2} \mathrm{Zr}_{2} \mathrm{O}_{7}$ is beneficial to improve mechanical properties and 
thermophysical properties. Among the $\mathrm{RE}^{3+}$, Sc has the smallest atomic radius. Our previous research results show that the addition of $\mathrm{Sc}^{3+}$ can increase the fracture toughness and TEC of $\mathrm{Gd}_{2} \mathrm{Zr}_{2} \mathrm{O}_{7}$ [18-20]. However, in previous studies, the doping amount of Sc was not optimized, and the solid solution mechanism of Sc in GZO lattice was not clarified theoretically.

Thermal shock resistance behavior, sintering resistance and phase stability of TBCs at high temperature are of great theoretical significance for the optimization design of aeroengine. Rare earth zirconate coating is resistant to sintering at high temperature, and is not easy to undergo phase transformation, but its fracture toughness and thermal expansion coefficient are relatively low, which will lead to poor thermal shock lifetime. M. Karabas [21] found that the thermal cycle life of $\mathrm{La}_{2} \mathrm{Zr}_{2} \mathrm{O}_{7}$ can be improved by doping rare earth elements. Guo et al. [22] studied the high temperature stability and thermal shock resistance of $\left(\mathrm{Gd}_{0.9} \mathrm{Yb}_{0.1}\right)_{2} \mathrm{Zr}_{2} \mathrm{O}_{7}$, and found that $\left(\mathrm{Gd}_{0.9} \mathrm{Yb}_{0.1}\right)_{2} \mathrm{Zr}_{2} \mathrm{O}_{7}$ can still maintain good phase stability at $1600{ }^{\circ} \mathrm{C}$, and the thermal cycle life is more than 3700 times. Other studies have shown that the design of double- ceramic-layer (DCL) TBCs structure can also improve the thermal shock lifetime, and YSZ coating can effectively alleviate the thermal stress at high temperature [23-25]. According to the above reports, rare earth zirconate materials have good phase stability at high temperature, and the thermal shock resistance can be improved by doping rare earth elements. 
The first-principles calculation method based on density functional theory has developed into an important method to predict the properties of materials in recent years, and has been used by many scholars to study the effect of rare-earth doping on the properties of rare earth zirconate [26-29]. Li et al. [27] found by first-principles calculation that doping $\mathrm{Sm}^{3+}$ in $\mathrm{La}_{2} \mathrm{Zr}_{2} \mathrm{O}_{7}$ could improve the mechanical and thermal properties, and $\mathrm{LaSmZr}_{2} \mathrm{O}_{7}$ has the optimal mechanical and thermal properties when the Sm content is 50 at. \%. Zhao et al. [28] used density functional theory and found that the Young's modulus, Debye temperature and thermal conductivity of $\mathrm{Gd}_{2} \mathrm{Zr}_{2} \mathrm{O}_{7}$ decrease with the Th content. Xiao et al. [29] used first-principles calculation method and found that the Young's modulus of $\mathrm{Gd}_{2} \mathrm{Zr}_{2} \mathrm{O}_{7}$ decreases by 22.2-59.9 GPa with the Ce content, and the thermal conductivity decreases by $21 \%$ after completely replacing $\mathrm{Ce}$ at $\mathrm{Zr}$ site. However, the above doping models are established by replacing the REsite or Zr-site in the pyrochlore lattice, and the interstitial model is not studied. Additionally, the solid solution mechanism of doped atoms has not been analyzed completely.

Sc has been proved to be a very effective dopant, which can significantly improve the mechanical and thermal properties of $\mathrm{Gd}_{2} \mathrm{Zr}_{2} \mathrm{O}_{7}$, but the solution mechanism and the optimal doping amount are still unclear. For TBC's application, its thermal shock and sintering behavior need to be investigated. Therefore, this study intends to clarify the 
solution mechanism of $\mathrm{Sc}$ doped $\mathrm{Gd}_{2} \mathrm{Zr}_{2} \mathrm{O}_{7}$ (Sc content is 16.67 at. \%) by first-principles method and optimize the doping amount of Sc through the change of mechanical and thermophysical properties, and investigate its thermal shock resistance behavior and sintering behavior under long-term heat treatment conditions.

\section{Theoretical calculation methods and experimental procedure}

\subsection{Theoretical calculation method}

The theoretical calculations were carried out by the Vienna Ab initio Simulation Package (VASP) software based on density functional theory (DFT) [30]. The projector augmented wave (PAW) method was used to describe the interaction between electrons and ions, and the generalized gradient approximation (GGA) was used to describe the electron exchange correlation potential $[31,32]$. In all calculations, the plane wave cutoff energy was set to $500 \mathrm{eV}$ and the $\mathrm{k}$ point is $3 \times 3 \times 3$. The convergence criterion of structural optimization was that the stress of each atom was less than $0.01 \mathrm{eV} /$ atom. In this work, $\mathrm{Gd}_{2} \mathrm{Zr}_{2} \mathrm{O}_{7}$ pyrochlore structure was first established, and then several possible models of $\mathrm{Sc}$ doped $\mathrm{Gd}_{2} \mathrm{Zr}_{2} \mathrm{O}_{7}$ solid solution was examined. For the strong interactions caused by the $4 \mathrm{f}$ electrons of $\mathrm{Gd}$, we did not adopt the Hubbard $\mathrm{U}$ correction method. The $4 \mathrm{f}$ electrons are regarded as core states, because $4 \mathrm{f}$ electrons do not affect the calculated results of mechanical and thermodynamic properties [33, 34].

In order to elucidate the solid solution mechanism of Sc atom in $\mathrm{Gd}_{2} \mathrm{Zr}_{2} \mathrm{O}_{7}$ lattice, the 
defect formation energies of different doping models were calculated based on the following equation [35]:

$$
\mathrm{E}_{\mathrm{f}}=\mathrm{E}_{\text {tot }}[\text { defect }]-\mathrm{E}_{\text {bulk }}[\text { perfect }]-\sum_{\mathrm{i}} \mathrm{n}_{\mathrm{i}} \mu_{\mathrm{i}}
$$

where $E_{\text {tot }}[\mathrm{defect}]$ is the energy of the crystal after doping, $\mathrm{E}_{\text {bulk }}$ [perfect] is the energy of an undoped perfect crystal, $n_{i}$ is the number of doping atoms $i$, and if this atom is added to the system, $\mathrm{n}>0$, if this atom is removed from the system, $\mathrm{n}<0$; and $\mu$ is the chemical potential of the corresponding atom.

After calculating the mechanical property parameters, the thermophysical properties were obtained, including longitudinal sound velocity $\mathrm{v}_{\mathrm{l}}$, transverse sound velocity $\mathrm{v}_{\mathrm{t}}$, average sound velocity $\mathrm{V}_{\mathrm{m}}$, Debye temperature $\Theta$ and minimum thermal conductivity $\mathrm{k}_{\min }$. The formulas used are as follows $[28,29]$ :

$$
\begin{gathered}
\mathrm{v}_{\mathrm{l}}=\sqrt{\left(\mathrm{B}+\frac{4}{3} \mathrm{G}\right) / \rho} \\
\mathrm{V}_{\mathrm{t}}=\sqrt{\mathrm{G} / \rho} \\
\mathrm{v}_{\mathrm{m}}=\left[\frac{1}{3}\left(\frac{2}{\mathrm{v}_{1}^{3}}+\frac{1}{\mathrm{v}_{\mathrm{t}}^{3}}\right)\right]^{-\frac{1}{3}} \\
\Theta=\frac{\mathrm{h}}{\mathrm{k}_{\mathrm{B}}}\left[\frac{3 \mathrm{n}}{4 \pi}\left(\frac{\mathrm{N}_{\mathrm{A}} \rho}{\mathrm{M}}\right)\right]^{\frac{1}{3}} \mathrm{v}_{\mathrm{m}}
\end{gathered}
$$

The minimum thermal conductivity is calculated by Clarke's model and Cahill's model respectively, with the following formulas [28, 29]:

$$
\begin{aligned}
& \mathrm{K}_{\min }^{\text {Clarke }}=0.87 \mathrm{k}_{\mathrm{B}} \mathrm{M}_{\mathrm{a}}^{-\frac{2}{3}} \mathrm{E}^{\frac{1}{2}} \rho^{\frac{1}{6}} \\
& \mathrm{k}_{\min }^{\text {Cahill }}=\frac{\mathrm{k}_{\mathrm{B}}}{2.48}\left(\frac{\mathrm{n}}{\mathrm{V}}\right)^{\frac{2}{3}}\left(\mathrm{v}_{l}+2 \mathrm{v}_{\mathrm{t}}\right)
\end{aligned}
$$

Where B is bulk modulus, $\mathrm{G}$ is shear modulus, $\mathrm{E}$ is Young's modulus, $\rho$ is density, $\mathrm{n}$ is the number of atoms in the crystal, $\mathrm{V}_{\mathrm{m}}$ is the volume of unit cell, $\mathrm{h}$ is Planck constant, 
$\mathrm{N}_{\mathrm{A}}$ is Avogadro constant, $\mathrm{k}_{\mathrm{B}}$ is Boltzmann constant, $\mathrm{M}$ is Molar mass, and $\mathrm{M}_{\mathrm{a}}$ is the average mass per atom.

\subsection{Experimental procedure}

Sc-doped $\mathrm{Gd}_{2} \mathrm{Zr}_{2} \mathrm{O}_{7}(\mathrm{Gd}-\mathrm{Sc})$ powders were prepared by a chemical precipitation and calcination method [36, 37]. Firstly, $\mathrm{Gd}_{2} \mathrm{O}_{3}, \mathrm{Sc}_{2} \mathrm{O}_{3}$ and $\mathrm{ZrOCl}_{2} \cdot 8 \mathrm{H}_{2} \mathrm{O}(99.9 \%$; JiangTian Chemical, Tianjin) was respectively weighed according to the molar ratio of 5: 1: 12. $\mathrm{Gd}_{2} \mathrm{O}_{3}$ and $\mathrm{Sc}_{2} \mathrm{O}_{3}$ were dissolved into excessive concentrated nitric acid (65\%; Jiang-Tian Chemical, Tianjin) to obtain $\mathrm{Gd}\left(\mathrm{NO}_{3}\right)_{3}$ and $\mathrm{Sc}\left(\mathrm{NO}_{3}\right)_{3}$, and $\mathrm{ZrOCl}_{2} \cdot 8 \mathrm{H}_{2} \mathrm{O}$ was dissolved in deionized water. Then the solutions were mixed evenly and slowly dripped into excessive ammonia water with mechanically stirring and ultrasonic oscillated to obtain white precipitation, which was filtered and washed several times with deionized water and anhydrous ethanol until PH 7 was reached. The obtained powders were dried at $120^{\circ} \mathrm{C}$ for $10 \mathrm{~h}$ and calcined at $900{ }^{\circ} \mathrm{C}$ for $5 \mathrm{~h}$ for crystallization. Gd-Sc and YSZ powders were agglomerated into microscopic particles by a spray drying method before spraying. The parameters of spray drying were as follows: The inlet and outlet temperatures were $240{ }^{\circ} \mathrm{C}$ and $100{ }^{\circ} \mathrm{C}$, respectively. The feed rate is 100 $\mathrm{g} / \mathrm{min}$.

Gd-Sc coating and Gd-Sc/YSZ double-ceramic-layer coating (DCL) TBCs were produced by air plasma spraying (APS) (Metro $7 \mathrm{M}$ ), the spraying parameters were 
shown in Table 1. The bond coat and the substrate were NiCoCrAlY (Shenyang Liming Aero Engine Group Corporation Ltd, 53-91 $\mu \mathrm{m}$ ) and Ni-based superalloy (DZ125), respectively. The compositions of them are listed in Table 2. When preparing double layer coating, YSZ coating was first sprayed on the bond coat, followed by the Gd-Sc coating.

Thermal shock tests were conducted by a water quenching method. When the temperature of the furnace was reached $1050{ }^{\circ} \mathrm{C}, \mathrm{Gd}-\mathrm{Sc}$ TBCs and Gd-Sc/YSZ DCL TBCs were put into the furnace and held for 10 minutes, followed by putting it into deionized water to room temperature. This process was defined as a thermal cycle and the termination condition was that the spallation area of the coating surface exceeds $20 \%$. The sintering behavior of Gd-Sc coatings were investigated at $1400{ }^{\circ} \mathrm{C}$ in a furnace (SK-G08163, China) for 20, 50, 100 and $200 \mathrm{~h}$.

Phase compositions of samples were determined by a D8 Advance Bruker diffractometer using $\mathrm{Cu} \mathrm{K} \alpha$ radiation, the parameters were as follows: the voltage and current was $40 \mathrm{kV}$ and $40 \mathrm{~mA}$, and the scanning range of $2 \theta$ was $20^{\circ} \sim 80^{\circ}$ with a rate of $6 \%$ min. The high temperature stability of Gd-Sc powders was examined by STA449C thermal analyzer, with the parameters as follows: the heating rate is $10{ }^{\circ} \mathrm{C} / \mathrm{min}$ and the temperature range is from room temperature to $1450{ }^{\circ} \mathrm{C}$. The surface morphologies, cross-sectional microstructure and composition analysis were observed 
by scanning electron microscope (SEM; Nanosem 430, FEI, USA) equipped with energy dispersive spectroscopy (EDS, IE 350).

\section{Results and discussion}

\subsection{Structural properties of $\mathrm{Gd}_{2} \mathrm{Zr}_{2} \mathrm{O}_{7}$}

The optimized $\mathrm{Gd}_{2} \mathrm{Zr}_{2} \mathrm{O}_{7}$ model is shown in Fig. 1. The structure exhibits a typical pyrochlore structure with $16 \mathrm{Gd}, 16 \mathrm{Zr}$ and $56 \mathrm{O}$ atoms. In the lattice, Gd occupies $16 \mathrm{~d}$ $(0.5,0.5,0.5), \mathrm{Zr}$ occupies $16 \mathrm{c}(0,0,0)$, and the $\mathrm{O}$ has two types of sites, i.e., $48 \mathrm{f}(\mathrm{x}$, $0.125,0.125)$ and $8 \mathrm{~b}(0.375,0.375,0.375)$. In addition, there is an unoccupied oxygen vacancy of $8 \mathrm{a}(0.125,0.125,0.125)$ in $\mathrm{Gd}_{2} \mathrm{Zr}_{2} \mathrm{O}_{7}$ lattice.

The two most important parameters for describing the structure of pyrochlore are the lattice constant $a_{0}$ and the atomic coordinate parameter XO-48f. The Xo-48f is an important parameter for the degree of structural disorder, with a value between 0.3125 and 0.375 [36]. When $x=0.3125$, it is an ideal pyrochlore structure, while when $x=0.375$, the system exhibits a disordered fluorite structure, that is, a larger value of $\mathrm{x}_{\mathrm{O}-48 \mathrm{f}}$ means a more disordered lattice structure [39]. After completing structural relaxation, the results of $a_{0}, \mathrm{XO}_{\mathrm{O}-48 \mathrm{f}}$ and density of the $\mathrm{Gd}_{2} \mathrm{Zr}_{2} \mathrm{O}_{7}$ model are obtained as shown in Table 3 , which are $10.600 \AA, 0.3386$ and $6.79 \mathrm{~g} / \mathrm{cm}^{3}$, respectively, showing agreement with the published values [40-43]. The above part demonstrates the reliability of our calculation results. 


\subsection{Solid solution mechanism of Sc-doped $\mathrm{Gd}_{2} \mathrm{Zr}_{2} \mathrm{O}_{7}$}

In $\mathrm{Gd}_{2} \mathrm{Zr}_{2} \mathrm{O}_{7}$ lattice, the doped Sc has two possible sites, i.e., interstitial site and substitution for Gd. In order to determine the solid solution mechanism of Sc in the lattice, we established models with one Sc atom, two atoms, three atoms and four atoms, which were named $\mathrm{Gd}_{\mathrm{Sc}-1 \text {-inter }}$ and $\mathrm{Gd}_{\mathrm{Sc}-1 \text {-sub }}, \mathrm{Gd}_{\mathrm{Sc}-2 \text {-inter }}$ and $\mathrm{Gd}_{\mathrm{Sc}-2 \text {-inter+sub }}, \mathrm{Gd}_{\mathrm{Sc}-3 \text {-inter }}$ and

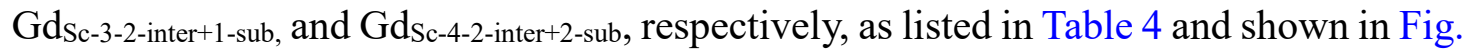
2. The subscripts of inter and sub stand for a Sc atom occupying an interstitial site and substituting for $\mathrm{Gd}$, respectively. The interstitial sites are $32 \mathrm{e}(0.25,0.25,0.25)$, which is the most stable interstitial site in pyrochlore structure [35]. The Gd site farthest from the $32 \mathrm{e}$ is selected as the substitution site.

Defect formation energy is an important parameter to determine the mechanism of point defect formation. The smaller the value, the easier the doped atom can enter the lattice $[35,44-45]$. The calculated formation energy values of above models are shown in Table 4. According to the calculation results, the solution mechanisms of Sc atoms in the $\mathrm{Gd}_{2} \mathrm{Zr}_{2} \mathrm{O}_{7}$ lattice are analyzed as follows: one $\mathrm{Sc}$ atom is easier to enter the interstitial site of the lattice, because the formation energy of $\operatorname{Gd}_{\mathrm{Sc}-1-\text { inter }}(0.141)$ is obviously smaller than that of $\operatorname{Gd}_{\mathrm{Sc}-1-\mathrm{sub}}$ (1.269), which is also consistent with our previous experimental results [17]. It is found that the formation energy of $\mathrm{Gd}_{\mathrm{Sc}-2 \text {-inter }}$ is

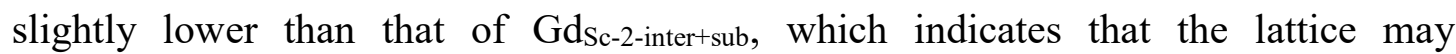
accommodate two interstitial $\mathrm{Sc}$ atoms but the second atom has some tendency to 
substitute for Gd. However, when three Sc atoms were added, we found that the

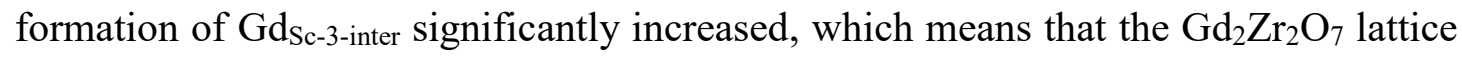
has no ability to accommodate three interstitial Sc atoms; in the case of $\mathrm{Gd}_{\mathrm{Sc}-3-2 \text { inter+1-sub }}$ model, the formation energy decreases significantly, suggesting that the third atom has to substitute for Gd.

The calculated lattice constant values are also listed in Table 4, and shown in Fig. 3 with variation of the Sc contents. The lattice constant increases to $10.646 \AA$ when the Sc content is below 11.11 at. \%, followed by a decrease. The increase is due to the presence of interstitial Sc atoms causing lattice expansion, and the decrease could be attributed to the smaller Sc substitution for Gd. Note that when the Sc content is above 5.88 at. $\%$, the increase rate of lattice constant is reduced. This indicates that the second Sc atom has some possibility to substitute for $\mathrm{Gd}$, offsetting the lattice expansion, which agrees with the formation energy calculation results. As a result, one could conclude that the interstitial Sc concentration in $\mathrm{Gd}_{2} \mathrm{Zr}_{2} \mathrm{O}_{7}$ lattice might be less than $11.11 \%$, which is consistent with our previous experimental results [18].

According to the change trend of the defect formation energy and lattice constant, the solid solution mechanism of $\mathrm{Sc}$ in $\mathrm{Gd}_{2} \mathrm{Zr}_{2} \mathrm{O}_{7}$ lattice might be clear: when the Sc content is 5.88 at. \%, the $\mathrm{Sc}$ atom enter the interstitial sites (32e) in the lattice; when the Sc content is 5.88 at. $\%-11.11$ at. $\%$, the interstitial $\mathrm{Sc}$ atoms reach saturation, after that the 
doped Sc begin to substitute for Gd.

3.3 Mechanical and thermophysical properties of Sc-doped $\mathrm{Gd}_{2} \mathrm{Zr}_{2} \mathrm{O}_{7}$

Based on the fully optimized model, we calculated the mechanical properties of Sc

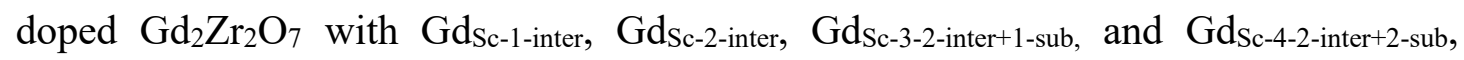
including elastic constants, bulk modulus B, shear modulus G and Young's modulus E. For cubic system, there are three independent elastic constants $\mathrm{C}_{11}, \mathrm{C}_{12}$ and $\mathrm{C}_{44}$. The calculated results are shown in Table 5. For $\mathrm{Gd}_{2} \mathrm{Zr}_{2} \mathrm{O}_{7}$, there are some differences between our calculated results and values in the literature $[29,34]$. The reason may be that the pseudopotential we used is different from that in the literature. For the ceramic system, we did not consider the spin polarization in the calculation process, while the results in the literature considered it $[29,34]$. However, for the bulk elastic modulus B, shear elastic modulus G and Young's elastic modulus E, our calculated results are in good agreement with the experimental values, which reveals the reliability of our calculated results.

For the cubic system, the elastic constants $\mathrm{C}_{11}, \mathrm{C}_{12}$ and $\mathrm{C}_{44}$ must meet the following three criteria to be mechanically stable: $\mathrm{C}_{11}+2 \mathrm{C}_{12}>0 ; \mathrm{C}_{44}>0 ; \mathrm{C}_{11}-\mathrm{C}_{12}>0$ [46]. According to the calculation results in Table 5, all models are mechanically stable. The variation trend of elastic constant and elastic modulus with the Sc content is shown in Fig. 4. It can be seen from Fig. $4 \mathrm{a}$ that $\mathrm{C}_{11}, \mathrm{C}_{12}$ and $\mathrm{C}_{44}$ have the lowest value when the 
Sc doping amount is $5.88 \%$. Fig. 4 b shows the bulk modulus B, shear modulus $\mathrm{G}$ and Young's modulus E. When the Sc content is $5.88 \%$, bulk modulus B decreases to the lowest value, and then increases slowly with the increase of Sc content. The shear modulus G decreases gently with the increase of Sc content, which is consistent with the research results of Th-doped $\mathrm{Gd}_{2} \mathrm{Zr}_{2} \mathrm{O}_{7}$, Ti-doped $\mathrm{Gd}_{2} \mathrm{Zr}_{2} \mathrm{O}_{7}$ and La-doped $\mathrm{Gd}_{2} \mathrm{Zr}_{2} \mathrm{O}_{7}$ $[28,29]$. Note that doping Sc atom could reduce Young's modulus E by $50-73 \mathrm{GPa}$. This is because doping smaller Sc atom into $\mathrm{Gd}_{2} \mathrm{Zr}_{2} \mathrm{O}_{7}$ lattice introduce size and coupling force mismatch, which causes fluctuation of strain field and lattice softening, resulting in a significant decrease of Young's modulus [47]. For TBC applications, a low Young's modulus is desirable, which means large strain tolerance of coatings beneficial for thermal shock resistance of TBCs [48].

The calculated results of Pugh's indicator $(\mathrm{G} / \mathrm{B})$ and Poisson ratios $(\sigma)$ of Sc doped $\mathrm{Gd}_{2} \mathrm{Zr}_{2} \mathrm{O}_{7}$ with $\mathrm{Gd}_{\mathrm{Sc}-1 \text {-inter, }}, \mathrm{Gd}_{\mathrm{sc}-2 \text {-inter, }}, \mathrm{Gd}_{\mathrm{sc}-3-2 \text {-inter+1-sub, and }} \mathrm{Gd}_{\mathrm{Sc}-4-2 \text {-inter+2-sub }}$ are listed in Table 6. G/B is an important index to describe brittle toughness of materials, with a critical value of 0.5 , above which the material exhibits brittleness [49]. In other words, the lower the $\mathrm{G} / \mathrm{B}$ is, the better toughness the material has. Poisson's ratio $\sigma$ is also another an important parameter to describe the toughness of materials. For ductile materials, the Poisson's ratio is 0.33 , while for strong covalent crystals, the Poisson's ratio is 0.1 [50]. In other words, a higher the Poisson's ratio means better toughness of materials. The calculated G/B and Poisson's ratios of $\mathrm{Gd}_{2} \mathrm{Zr}_{2} \mathrm{O}_{7}$ are 0.545 and 0.269 , 
which are in good agreement with the literature values $[28,51]$. Fig. 5 shows the variation of Pugh's indicator(G/B) and Poisson ratios $(\sigma)$ with the Sc content. With the increase of the Sc content, G/B decreases first followed by an increase when the doping content reach $16.67 \%$, while $\sigma$ increases first and then shows a decrease. At a Sc doping level of $16.67 \%$, G/B has the lowest value of 0.408 , and $\sigma$ has the highest value of 0.32 , suggesting that the material with this composition has the highest toughness.

The thermophysical properties of different Sc-doped $\mathrm{Gd}_{2} \mathrm{Zr}_{2} \mathrm{O}_{7}$ models are listed in Table 7. The calculated Debye temperature of $\mathrm{Gd}_{2} \mathrm{Zr}_{2} \mathrm{O}_{7}$ is $508.506 \mathrm{~K}$, which is close to the calculated value of $520.7 \mathrm{~K}$ by Zhao et al. [28] and the experimental $513.4 \mathrm{~K}$ by Shimamura et al. [51]. After doping Sc atoms into $\mathrm{Gd}_{2} \mathrm{Zr}_{2} \mathrm{O}_{7}$, longitudinal sound velocity $\mathrm{v}_{\mathrm{l}}$, transverse sound velocity $\mathrm{v}_{\mathrm{t}}$ and average sound velocity $\mathrm{v}_{\mathrm{m}}$ all decrease, which leads to the decrease of Debye temperature. The variation of Debye temperature $\Theta$ (a) and thermal conductivity (b) with the Sc content is shown in Fig. 6. 5.88 \% Sc doping into $\mathrm{Gd}_{2} \mathrm{Zr}_{2} \mathrm{O}_{7}$ lattice reduces the Debye temperature by $72 \mathrm{~K}$, while there is a slight increase in the Debye temperature when the doping content reach $11.11 \%$, and then it decreases again. Debye temperature of a material can reflect its TEC [53]. A low Debye temperature suggests weak interaction between atoms in the lattice, which indicates a high coefficient of thermal expansion [29]. For TBC materials, a high coefficient of thermal expansion benefits to reduce the thermal mismatch between the coating and substrate. 
The minimum thermal conductivities were calculated based on Cahill's model and Clarke's model as listed in Table 7, which are present in Fig. $6 \mathrm{~b}$ as the function of the Sc content. The calculated thermal conductivities of $\mathrm{Gd}_{2} \mathrm{Zr}_{2} \mathrm{O}_{7}$ are $1.23 \mathrm{~W} / \mathrm{m} \cdot \mathrm{K}$ by Clarke's model and $1.35 \mathrm{~W} / \mathrm{m} \cdot \mathrm{K}$ by Cahill's model, which are in agreement with the calculated value of $1.29 \mathrm{~W} / \mathrm{m} \cdot \mathrm{K}$ and $1.35 \mathrm{~W} / \mathrm{m} \cdot \mathrm{K}$ by Zhao et al. [28, 29]. Our calculated results are also within the experimental results range of $1.0-1.6 \mathrm{~W} / \mathrm{m} \cdot \mathrm{K}$ [54-56]. It can be seen from Fig. $6 \mathrm{~b}$ that the minimum thermal conductivity calculated by Cahill's model is slightly higher than that obtained Clarke's model, which is also in line with the calculation trend of other scholars $[28,29]$. Comparing curves in Fig. 6a and 6b, it could be found that the variation trend of thermal conductivity is similar with that of Debye temperature with the increase of Sc content. Compared with $\mathrm{Gd}_{2} \mathrm{Zr}_{2} \mathrm{O}_{7}, 5.88 \%$ Sc doped $\mathrm{Gd}_{2} \mathrm{Zr}_{2} \mathrm{O}_{7}$ has a significant decrease in the minimum thermal conductivity, but further increasing the Sc doping content enhances the thermal conductivity; when the Sc content is above $11.11 \%$, the minimum thermal conductivity has a declining trend, but the decrease rate becomes slow at higher doping levels. It can be seen from the variation of Debye temperature and thermal conductivity that too much Sc doping has no obvious effect on increasing TEC and decreasing thermal conductivity.

Thermal conductivity is closely related to phonon scattering [22]. When the Sc content is $5.88 \%$, Sc atoms enter the interstitial sites of $\mathrm{Gd}_{2} \mathrm{Zr}_{2} \mathrm{O}_{7}$, which enhances phonon 
scattering. However, in order to balance the charge, oxygen vacancies are consumed, which would reduce the phonon scattering, but the thermal conductivity is still greatly reduced, which indicates that interstitial doping atoms play a significant role in enhancing phonon scattering. With the increase of Sc content, Gd is gradually replaced by $\mathrm{Sc}^{3+}$. Due to the smaller $\mathrm{Sc}^{3+}$ replaces $\mathrm{Gd}^{3+}$, resulting in $\mathrm{Sc}^{3+}$ is loosely bound in an oversized atomic cage and does not easily vibrate with other phonons, acting like a local "rattler", which enhances the scattering of phonons and leads to a decrease in thermal conductivity, but its enhancement effect is not as significant as that brought by interstitial atoms, which leads to a slow decline in thermal conductivity [57].

According to the theoretical calculation, the mechanical and thermophysical properties of $\mathrm{Gd}_{2} \mathrm{Zr}_{2} \mathrm{O}_{7}$ can be designed by Sc doping. When the Sc content is less than $11.11 \%$, all Sc atoms enter the interstitial sites of $\mathrm{Gd}_{2} \mathrm{Zr}_{2} \mathrm{O}_{7}$ lattice. Then, the $\mathrm{Gd}^{3+}$ sites would be gradually replaced by $\mathrm{Sc}^{3+}$ with the increase of $\mathrm{Sc}$ content. Young's modulus decreases by 50-64 GPa after doping Sc atom, which benefits the thermal shock resistance and high temperature stability of the coating. However, when the content of Sc exceeds $16.67 \%$, the decreasing trend slows down. The toughness of the material can be improved obviously by doping Sc atoms, but when Sc content exceeds $16.67 \%$, the toughness begins to decrease. Similarly, the downward trend of Debye temperature and thermal conductivity begins to slow down after Sc content exceeds 16.67\%. Therefore, when the content of Sc is about $16.67 \%$, all aspects of the performance may 
be the most suitable.

\subsection{Preparation of Gd-Sc TBCs and their sintering behavior}

The XRD patterns of the prepared Gd-Sc powder, Gd-Sc TBCs and Gd-Sc/YSZ DCL TBCs (Sc content is 16.67 at. \%) are shown in Fig. 7a. All the patterns exhibit similar appearance, which have diffraction peaks ascribed to disordered defect fluorite. This indicates that during plasma spraying processes, Gd-Sc powder keeps phase stability, and our spraying parameters are suitable. Fig. 7b shows the DSC curve of Gd-Sc powder at a temperature range of $25{ }^{\circ} \mathrm{C}$ to $1450{ }^{\circ} \mathrm{C}$. There is an endothermic peak at $388^{\circ} \mathrm{C}$, which may be caused by evaporative heat absorption of crystalline water. No other heat absorption or exothermic peaks can be observed during the whole heating process, which indicates that Gd-Sc can maintain good high temperature stability up to $1450{ }^{\circ} \mathrm{C}$. This is beneficial for Gd-Sc coatings used at elevated temperatures.

Cross-sectional microstructures of Gd-Sc TBCs and Gd-Sc/YSZ DCL TBCs are shown in Fig. 8a and Fig. 8b, respectively. The Gd-Sc coating and YSZ coating show a typical layered structure, and both types of TBCs have integral interface, where there are no obvious defects such as gaps and cracks. In Gd-Sc TBCs, the thickness of the Gd-Sc coating is $\sim 120 \mu \mathrm{m}$. In Gd-Sc/YSZ DCL TBCs, the thickness of Gd-Sc coating is $\sim 80$ $\mu \mathrm{m}$ and that of YSZ coating is $\sim 150 \mu \mathrm{m}$. 
The XRD patterns of Gd-Sc/YSZ coatings after heat treatment tests at $1400{ }^{\circ} \mathrm{C}$ are shown in Fig. 9. It can be seen that the patterns of the heat-treated coatings are similar to that of the as-fabricated coating except that the peaks become sharp, which indicates the crystallization degree of the coatings increases after heat treatments. No new phases are formed in the coatings during sintering, indicating that Gd-Sc coating has excellent phase stability at $1400{ }^{\circ} \mathrm{C}$.

The surface morphologies of Gd-Sc coatings after heat treatments at $1400{ }^{\circ} \mathrm{C}$ are shown in Fig. 10. During the first $100 \mathrm{~h}$ heat treatment, the coating surface morphologies have little change indicative of excellent sintering resistance. Prolonging the heat treatment to $200 \mathrm{~h}$, many micro-cracks disappear and some large cracks appear, and in the enlarged image (Fig. 10d), one can found that the grains have some growth. This indicates that the coating experiences some sintering during long-term heat treatment at $1400{ }^{\circ} \mathrm{C}$, but the sintering degree is not severe, and the coating almost keeps its original morphology.

The fracture surface morphology of Gd-Sc coatings after heat treatments at $1400{ }^{\circ} \mathrm{C}$ are shown in Fig. 11. It can be seen that the layered structure can be clearly observed in the coatings after $20 \mathrm{~h}, 50 \mathrm{~h}$ and $100 \mathrm{~h}$ heat treatments. When the heat treatment time is extended to $200 \mathrm{~h}$, the lamellar structure is not obvious, microcracks and pores are closed, and some vertical cracks begin to appear, which indicates that the coating turns 
to sintering. The reason for the vertical cracks may be that sufficient temperature and time provide driving force for the growth of grains during heat treatment. At the beginning of sintering, grains contact with each other, resulting in sintering neck, microcracks and voids gradually heal; with the extension of time to the later stage of sintering, the micro-cracks and voids disappear, which reduces the strain tolerance and thermal insulation of the coating. The thermal stress accumulated during long-term heat treatment couldn't be released through micro-cracks and voids, resulting in stress concentration, which results in cracks during the cooling phase. This will not benefit the thermal shock resistance, corrosion resistance and other properties of the coating, and greatly reduces the service life of the coating.

\subsection{Thermal cycling behavior of Gd-Sc TBCs and Gd-Sc/YSZ DCL TBCs}

The macroscopic morphologies evolution of Gd-Sc TBCs and Gd-Sc/YSZ DCL TBCs during thermal cycling tests are shown in Fig. 12. Both types of TBCs spalled from the edge. After 75 and 215 thermal cycles, the spallation area of Gd-Sc TBCs and GdSc/YSZ DCL TBCs reaches $20 \%$ of the total area, respectively. The superalloy substrates become black, which indicates that substrate oxidation takes place during the thermal cycling test. By comparison, Gd-Sc/YSZ DCL TBCs exhibit much longer lifetime than that of Gd-Sc TBCs, revealing that double-layer design could significantly improve the thermal shock resistance of TBCs. 
The XRD patterns of the Gd-Sc TBCs and Gd-Sc/YSZ DCL TBCs after thermal cycling tests are shown in Fig. 13. During the tests, Gd-Sc coatings has no phase decomposition, indicating that the coatings have excellent phase stability. $\mathrm{AlNi}_{3}$ is detected in the GdSc TBCs after 75 thermal cycles, which is the component of the bonding coating [58, 59]. It could be presumed that some regions of Gd-Sc coating have spalled off, leaving the bond coat outside. After 215 thermal cycles, $\mathrm{t}^{\prime}-\mathrm{ZrO}_{2}$ and $\mathrm{NiO}$ are detected in the Gd-Sc/YSZ DCL TBCs. This indicates that the spallation may occur near the bond coat, causing the TGO being detected.

The spalling edge region and adjacent region of Gd-Sc TBCs and Gd-Sc/YSZ DCL TBCs are marked as A, B, C and D, respectively, as shown in Fig. 12b and d. Fig. 14a shows the cross-sectional morphology of region A. After 75 thermal cycles, the Gd-Sc coating has spalled, and there is a large delamination crack in the coating. The crosssection morphology of region B is shown in Fig. 14b. It can be seen that the coating delamination starts from the region near the bond coat. It has been reported that $\mathrm{Gd}_{2} \mathrm{Zr}_{2} \mathrm{O}_{7}$ can react with TGO during heat treatment, which causes stress growth and crack formation at the interface between $\mathrm{Gd}_{2} \mathrm{Zr}_{2} \mathrm{O}_{7}$ coating and the bond coat [23]. For Gd-Sc coating, it also has large possibility to react with TGO, resulting in delamination crack in the coating region near the bond coat. Additionally, although Gd-Sc has improved toughness compared with $\mathrm{Gd}_{2} \mathrm{Zr}_{2} \mathrm{O}_{7}$, its toughness is still not high enough to resist the thermal stress generated in the thermal cycle process, which inevitably leads 
to the formation of cracks in the Gd-Sc coating.

Fig. 15a shows the cross-sectional microstructure of region C. After 215 thermal cycles, the interface between Gd-Sc and YSZ coatings is well bonded, without any defect, and both coating maintains good structural integrity. However, a larger delamination crack forms in the YSZ coating, above which the coatings are spalled. The cross-sectional morphology of region D is shown in Fig. 15b. Although the coatings here are not spalled, some delamination cracks can be found in the YSZ coating, which could cause coating spallation like Fig. 15a by further thermal shock. At the interface between the YSZ coating and the bond coat, some dark contrast products are observed, which are denoted as E. EDS analysis results show that the product is mainly composed of $\mathrm{Ni}, \mathrm{Al}, \mathrm{O}$ and a small amount of Cr. Combined with the XRD results, we can determine that the products in this region are mainly $\mathrm{NiO}$, as well as some $\mathrm{Cr}$ and $\mathrm{Al}$ oxides, which is the component of TGO.

Based on the results of SEM and EDS, the failure mechanisms of Gd-Sc/YSZ DCL TBCs could be analyzed as follows. Since the bottom and side of substrate are not covered with the coating, and the thickness of the bond coat is thin, which results in serious oxidation of the alloy substrates and bond coat during thermal cycling. The thickness of the TGO increased with a larger volume expansion, thereby producing a large stress concentration near the oxidation product, resulting in the initiation and 
propagation of cracks, which lead to the YSZ coating cracking. Note that Gd-Sc coating still maintains good structural integrity and the interface with YSZ coating is intact. This is because the doping of Sc improves the toughness and TEC, and reduces the Young's modulus, which ensures the tolerance in the process of thermal cycle, and has a good thermal match with YSZ. YSZ coating plays a good buffer role during thermal cycling, and prevents the reaction of $\mathrm{Gd}-\mathrm{Sc}$ with the bond coat to form $\mathrm{GdAlO}_{3}$ phase. Therefore, Gd-Sc/YSZ DCL TBCs have better thermal shock resistance.

Thermal cycling life is an important index to evaluate the practical performance of TBCs. Long thermal cycle life is more suitable for TBCs candidate. There are many factors that affect the thermal cycle life, such as cooling rate, temperature, high temperature dwell time and so on. Under similar experimental conditions, the thermal cycling life of $\mathrm{La}_{2} \mathrm{Zr}_{2} \mathrm{O}_{7} / \mathrm{YSZ}-\mathrm{TBCs}$ is 160 times, $\mathrm{GdPO}_{4} / \mathrm{YSZ}-\mathrm{TBC}$ is 70 times and ( $\left.\mathrm{La}_{0.8} \mathrm{Eu}_{0.2}\right)_{2} \mathrm{Zr}_{2} \mathrm{O}_{7} / \mathrm{YSZ}-\mathrm{TBC}$ is 32 times [60-62]. The thermal cycling life of these new thermal barrier coatings is less than that of Gd-Sc/YSZ DCL TBCs. In particular, compared with $\mathrm{Gd}_{2} \mathrm{Zr}_{2} \mathrm{O}_{7}$, the thermal cycling life is increased by $55 \%$ [63]. Therefore, Gd-Sc/YSZ TBCs have excellent thermal shock resistance and good application prospects in the newly developed thermal barrier coating materials.

\section{Conclusions}

In this work, the first-principles method is used to study the solid solution mechanism 
of Sc atom in $\mathrm{Gd}_{2} \mathrm{Zr}_{2} \mathrm{O}_{7}$ lattice. The variation of mechanical and thermophysical properties of Sc-doped $\mathrm{Gd}_{2} \mathrm{Zr}_{2} \mathrm{O}_{7}$ (Gd-Sc) with the Sc content is also investigated. Based on theoretical calculation results, the Sc doping content was optimized. Then, Gd-Sc TBCs and Gd-Sc/YSZ TBCs were produced by air plasma spraying, and the phase composition, microstructure, sintering behavior and thermal cycling performance of the coatings were investigated. Following conclusions can be drawn:

(1) When the content of $\mathrm{Sc}$ is $5.88 \%$, Sc atoms occupies the interstitial sites in the $\mathrm{Gd}_{2} \mathrm{Zr}_{2} \mathrm{O}_{7}$ lattice because the formation energy of interstitial doping is significantly lower than that of substitution doping. The variation trend of the lattice constant shows that the Sc interstitial concentration might be less than $11.11 \%$. After that, Gd would be gradually replaced by Sc with the increase of the doping content.

(2) Compared with $\mathrm{Gd}_{2} \mathrm{Zr}_{2} \mathrm{O}_{7}$, Gd-Sc has lower Young's modulus and Pugh's indicator $(\mathrm{G} / \mathrm{B})$ and a higher Poisson ratio $(\sigma)$ suggesting better thermal shock resistance and higher toughness. At the Sc doping level of $16.67 \%$, Gd-Sc exhibited the lowest $\mathrm{G} / \mathrm{B}$ and the highest $\sigma$ indicative of the highest toughness. With the increase of the Sc content, the Debye temperature and thermal conductivity have similar variation trends, which have a significant decrease when doping $5.88 \% \mathrm{Sc}$, and then increase slightly followed by a decrease with further doping. When the Sc content exceeds $16.67 \%$, the decreasing trend of Debye temperature and thermal conductivity reduce. Therefore, the Sc doping content in $\mathrm{Gd}_{2} \mathrm{Zr}_{2} \mathrm{O}_{7}$ is optimized to be $16.67 \%$. 
(3) Gd-Sc coatings maintain excellent phase and structural stability after heat treatment at $1400{ }^{\circ} \mathrm{C}$ for $100 \mathrm{~h}$. The thermal shock resistance of Gd-Sc/YSZ DCL TBCs is better than that of Gd-Sc TBCs. Due to the improvement in the toughness and thermal expansion coefficient and the decrease in Young's modulus, Gd-Sc coatings have good structural integrity and excellent matching with YSZ coating during thermal cycling. In addition, YSZ coating plays a good buffer role during thermal cycling and prevents the reaction of Gd-Sc with the bond coat. Gd-Sc coatings reveal excellent thermal shock resistance and sintering resistance, which has a promising application prospect.

\section{Acknowledgments}

This research is sponsored by the National Natural Science Foundation of China (Grant No. 51971156) and National Science and Technology Major Project (Grant No. 2017VII-0007-010). First-principles calculation of this work was carried out on TianHe-1 (A) at National Supercomputer Center in Tianjin.

\section{References}

[1] H. Guo, S. Gong, H. Xu. Research progress on new high/ultra-high temperature thermal barrier coatings and processing technologies[J]. Acta Aeronaut. Astronaut. Sin. 35 (2014) 2722-2732.

[2] R. Vaßen, M.O. Jarligo, T. Steinke, et al. Overview on advanced thermal barrier 
coatings [J]. Surf. Coat. Technol. 205 (2010) 938-942.

[3] D. Liu, P. Jiang, R. Gao, et al. Experimental and numerical investigation on the thermal and mechanical behaviors of thermal barrier coatings exposed to CMAS corrosion [J]. J. Adv. Ceram. 10 (2021) 551-564.

[4] V. Kumar, K. Balasubramanian. Progress update on failure mechanisms of advanced thermal barrier coatings: A review[J]. Prog. Org. Coat. 90 (2016) 54-82.

[5] G. Mauer, M. O. Jarligo, D. E. Mack, et al. Plasma sprayed thermal barrier coatings: New materials, processing issues and solutions[J]. J. Therm. Spray Technol. 22 (2013) 646-658.

[6] A. K. Rai, M. P. Schmitt, R. S. Bhattacharya, et al. Thermal conductivity and stability of multilayered thermal barrier coatings under high temperature annealing conditions [J]. J. Eur. Ceram. Soc. 35 (2015) 1605-1612.

[7] A. Vaidya, V. Srinivasan, T. Streibl. Process maps for plasma spraying of yttriastabilized zirconia: An integrated approach to design, optimization and reliability[J]. Mater. Sci. Eng. A. 497 (2008) 239-253.

[8] A. Feuerstein, J. Knapp, T. Taylor, et al. Technical and economical aspects of current thermal barrier coating systems for gas turbine engines by thermal spray and EB-PVD: A review[J]. J. Therm. Spray Technol. 17 (2008) 199-213.

[9] J. W, H.B. Guo, Y. Z. Gao, et al. Microstructure and thermo-physical properties of yttria stabilized zirconia coatings with CMAS deposits [J]. J. Eur. Ceram. Soc. 31 (2011) 1881-1888. 
[10]Z. Zhao, H. Chen, H. Xiang, et al. High entropy defective fluorite structured rareearth niobates and tantalates for thermal barrier applications [J]. J. Adv. Ceram. 9 (2020) 303-311.

[11]Y. Zhang, L. Guo, X. Zhao, et al. Toughening effect of $\mathrm{Yb}_{2} \mathrm{O}_{3}$ stabilized $\mathrm{ZrO}_{2}$ doped in $\mathrm{Gd}_{2} \mathrm{Zr}_{2} \mathrm{O}_{7}$ ceramic for thermal barrier coatings [J]. Mater. Sci. Eng. A. 648 (2015) 385-391.

[12]C. Zhang, Y. Fan, J. Zhao, et al. Corrosion resistance of non-stoichiometric gadolinium zirconate fabricated by laser-enhanced chemical vapor deposition [J]. J. Adv. Ceram. 10 (2021) 520-528.

[13]K. M. Doleker, A. C. Karaoglanli. Comparison of oxidation behavior of YSZ and $\mathrm{Gd}_{2} \mathrm{Zr}_{2} \mathrm{O}_{7}$ thermal barrier coatings (TBCs)[J]. Surf. Coat. Technol. 318 (2017) 198207.

[14]R. Vaßen, E. Bakan, D. Mack, et al. Performance of YSZ and $\mathrm{Gd}_{2} \mathrm{Zr}_{2} \mathrm{O}_{7} / \mathrm{YSZ}$ double layer thermal barrier coatings in burner rig tests [J]. J. Eur. Ceram. Soc. 40 (2020) 480-490.

[15]F. N. Sayed, V. Grover, K. Bhattacharyya, et al. $\mathrm{Sm}_{2-\mathrm{x}} \mathrm{Dy}_{\mathrm{x}} \mathrm{Zr}_{2} \mathrm{O}_{7}$ Pyrochlores: Probing Order-Disorder Dynamics and Multifunctionality [J]. Inorg. Chem. 50 (2011) 2354-2365.

[16]A. N. Radhakrishnan, P. P. Rao, K. S. M. Linsa, et al. Thermal expansion behaviour of some rare earth oxide pyrochlores [J]. Mater. Res. Bull. 29 (1994) 759-766.

[17]K. S. Lee, K. I. Jung, Y. S. Heo, et al. Thermal and mechanical properties of sintered 
bodies and EB-PVD layers of $\mathrm{Y}_{2} \mathrm{O}_{3}$ added $\mathrm{Gd}_{2} \mathrm{Zr}_{2} \mathrm{O}_{7}$ ceramics for thermal barrier coatings [J]. J. Alloys Compd. 507 (2010) 448-455.

[18]C. Wang, L. Guo, Y. Zhang, et al. Enhanced thermal expansion and fracture toughness of $\mathrm{Sc}_{2} \mathrm{O}_{3}$-doped $\mathrm{Gd}_{2} \mathrm{Zr}_{2} \mathrm{O}_{7}$ ceramics [J]. Ceram. Int. 41 (2015) 1073010735.

[19]L. Guo, Y. Zhang, C. Wang, et al. Phase structure evolution and thermal expansion variation of $\mathrm{Sc}_{2} \mathrm{O}_{3}$ doped $\mathrm{Nd}_{2} \mathrm{Zr}_{2} \mathrm{O}_{7}$ ceramics [J]. Mater. Des. 82 (2015) 114-118.

[20]C. Zhang, M. Li, Y. Zhang, et al. Hot corrosion behavior of $\left(\mathrm{Gd}_{0.9} \mathrm{Sc}_{0.1}\right)_{2} \mathrm{Zr}_{2} \mathrm{O}_{7}$ in $\mathrm{V}_{2} \mathrm{O}_{5}$ molten salt at $700-1000{ }^{\circ} \mathrm{C}[\mathrm{J}]$. Ceram. Int. 43 (2017) 9041-9046.

[21]M. Karabas. Production and characterization of Nd and Dy doped lanthanum zirconate-based thermal barrier coatings [J]. Surf. Coat. Technol. 394 (2020) 125864.

[22]L. Guo, H. Guo, H. Peng, et al. Thermophysical properties of $\mathrm{Yb}_{2} \mathrm{O}_{3}$ doped $\mathrm{Gd}_{2} \mathrm{Zr}_{2} \mathrm{O}_{7}$ and thermal cycling durability of $\left(\mathrm{Gd}_{0.9} \mathrm{Yb}_{0.1}\right)_{2} \mathrm{Zr}_{2} \mathrm{O}_{7} / \mathrm{YSZ}$ thermal barrier coatings [J]. J. Eur. Ceram. Soc. 34 (2014) 1255-1263.

[23]M. Bahamirian, S.M.M. Hadavi, M. Farvizi, et al. Thermal durability of YSZ/nanostructured $\mathrm{Gd}_{2} \mathrm{Zr}_{2} \mathrm{O}_{7}$ TBC undergoing thermal cycling [J]. Oxid. Met. 92 (2019) 401-421.

[24]Z.Y. Shen, L.M. He, Z.H. Xu, et al. LZC/YSZ DCL TBCs by EB-PVD: Microstructure, low thermal conductivity and high thermal cycling life [J]. J. Eur. Ceram. Soc. 39 (2019) 1443-1450. 
[25]F. Zhou, Y. Wang, Z. Cui, et al. Thermal cycling behavior of nanostructured 8YSZ, SZ/8YSZ and 8CSZ/8YSZ thermal barrier coatings fabricated by atmospheric plasma spraying [J]. Ceram. Int. 43 (2017) 4102-4111.

[26]B. Liu, J. Zhao, Y. Liu, et al. Application of high-throughput first-principles calculations in ceramic innovation [J]. J. Mater. Sci. Technol. 88 (2021) 143-157.

[27]Y. Li, X. Meng, Q. Chen, et al. Electronic structure and thermal properties of $\mathrm{Sm}^{3+}$ doped $\mathrm{La}_{2} \mathrm{Zr}_{2} \mathrm{O}_{7}$ : First-principles calculations and experimental study [J]. J. Am. Ceram. Soc. 00 (2020) 1-14.

[28]F.A. Zhao, H.Y. Xiao, Z.J. Liu, et al. A DFT study of mechanical properties, thermal conductivity and electronic structures of Th-doped $\mathrm{Gd}_{2} \mathrm{Zr}_{2} \mathrm{O}_{7}[\mathrm{~J}]$. Acta Mater. 121 (2016) 299-309.

[29]F.A. Zhao, H.Y. Xiao, X.M. Bai, et al. Effects of doping $\mathrm{Yb}^{3+}, \mathrm{La}^{3+}, \mathrm{Ti}^{4+}, \mathrm{Hf}^{4+}, \mathrm{Ce}^{4+}$ cations on the mechanical properties, thermal conductivity, and electronic structures of $\mathrm{Gd}_{2} \mathrm{Zr}_{2} \mathrm{O}_{7}$ [J]. J. Alloys Compd. 776 (2019) 306-318.

[30]G. Kresse, J. Furthmüller. Efficient iterative schemes for ab initio total-energy calculations using a plane-wave basis set [J]. Phys. Rev. B, 54 (1996) 11169.

[31]G. Kresse, J. Furthmüller. Efficiency of ab-initio total energy calculations for metals and semiconductors using a plane-wave basis set [J]. Comput. Mater. Sci. 6 (1996) 15-50.

[32]J. Perdew, K. Burke, Y. Wang. Generalized gradient approximation for the exchange-correlation hole of a many-electron system [J]. Phys. Rev. B. 57 (1998) 
14999.

[33]F.A. Zhao, H.Y. Xiao, X.M. Bai, et al. Effects of Nd doping on the mechanical properties and electronic structures of $\mathrm{Gd}_{2} \mathrm{Zr}_{2} \mathrm{O}_{7}$ : a first-principles-based study [J]. J. Mater. Sci. 53 (2018) 16423.

[34]J. Feng, B. Xiao, C.L. Wan, et al. Electronic structure, mechanical properties and thermal conductivity of $\mathrm{Ln}_{2} \mathrm{Zr}_{2} \mathrm{O}_{7}(\mathrm{Ln}=\mathrm{La}, \mathrm{Pr}, \mathrm{Nd}, \mathrm{Sm}, \mathrm{Eu}$ and $\mathrm{Gd})$ pyrochlore [J]. Acta Mater. 59 (2011) 1742-1760.

[35]L. Yang, P. Wang, C. Zhang, et al. Composition-dependent intrinsic defect structures in pyrochlore $\mathrm{RE}_{2} \mathrm{~B}_{2} \mathrm{O}_{7}(\mathrm{RE}=\mathrm{La}, \mathrm{Nd}, \mathrm{Gd} ; \mathrm{B}=\mathrm{Sn}, \mathrm{Hf}, \mathrm{Zr})[\mathrm{J}]$. J. Am. Ceram. Soc. 103 (2020) 645-655.

[36]L. Guo, G. Li, Z.L. Gan, Effects of surface roughness on CMAS corrosion behavior for thermal barrier coating applications [J]. J. Adv. Ceram. 10 (2021) 472-481.

[37]R.B. Zhu, J.P. Zou, J. Mao, et al. Fabrication and growing kinetics of highly dispersed gadolinium zirconate nanoparticles [J]. Res. Appl. Mat. Sci. 1 (2019) 2834.

[38]G. Lumpkin, M. Pruneda, Susana Rios, et al. Nature of the chemical bond and prediction of radiation tolerance in pyrochlore and defect fluorite compounds [J]. J. Solid State Chem. 180 (2007) 1512-1518.

[39]C. Jiang, C. R. Stanek, K. E. Sickafus, et al. First-principles prediction of disordering tendencies in pyrochlore oxides [J]. Phys. Rev. B. 79 (2009) 104203.

[40]F. Luo, B. Li, Z. Guo, et al. Ab initio calculation of mechanical and thermodynamic 
properties of $\mathrm{Gd}_{2} \mathrm{Zr}_{2} \mathrm{O}_{7}$ pyrochlore [J]. Mater. Chem. Phys. 243 (2020) 122565.

[41]X.J. Wang, H.Y. Xiao, X.T. Zu, et al. Study of cerium solubility in $\mathrm{Gd}_{2} \mathrm{Zr}_{2} \mathrm{O}_{7}$ by DFT + U calculations [J]. J. Nucl. Mater. 419 (2011) 105-111.

[42]X. Lua, X. Shua, L. Wang, et al. Microstructure evolution of rapidly fabricated $\mathrm{Gd}_{2-}$ ${ }_{x} \mathrm{Nd}_{\mathrm{x}} \mathrm{Zr}_{2} \mathrm{O}_{7}(0.0 \leq \mathrm{x} \leq 2.0)$ by spark plasma sintering [J]. Ceram. Int. 44 (2018) $2458-2462$

[43]X. Lu, F. Dong, G. Song, et al. Phase and rietveld refinement of pyrochlore $\mathrm{Gd}_{2} \mathrm{Zr}_{2} \mathrm{O}_{7}$ used for immobilization of $\mathrm{Pu}$ (IV) [J]. J. Wuhan Univ. Technol. Materials Sci. Ed. 29 (2014) 233.

[44]F. Oba, M. Choi, A. Togo, et al. Point defects in $\mathrm{ZnO}$ : an approach from first principles [J]. Sci. Technol. Adv. Mater. 12 (2011) 1-14.

[45]C. Van, J. Neugebauer. First-principles calculations for defects and impurities: Applications to III-nitrides [J]. 95 (2004) 3851-3879.

[46]J. Wang, S. Yip, S. R. Phillpot, et al. Crystal instabilities at finite strain [J]. Phys. Rev. Lett. 71 (1993) 4182-4185.

[47]C. L. Wan, W. Pan, Q. Xu, et al. Effect of point defects on the thermal transport properties of $\left(\mathrm{La}_{\mathrm{x}} \mathrm{Gd}_{1-\mathrm{x}}\right)_{2} \mathrm{Zr}_{2} \mathrm{O}_{7}$ : Experiment and theoretical model [J]. Phys. Rev. B. 74 (2006) 144109.

[48]J. A. Thompson, T. W. Clyne. The effect of heat treatment on the stiffness of zirconia top coats in plasma-sprayed TBCs [J]. Acta Mater. 49 (2001) 1565-1575. [49]S.F. Pugh. XCII. Relations between the elastic moduli and the plastic properties of 
polycrystalline pure metals, The London, Edinburgh, and Dublin Philosophical Magazine and Journal of Science, 45 (1954) 823-843.

[50] J. Haines, J. M. Léger, G. Bocquillon, Synthesis and design of superhard materials [J]. Annu. Rev. Mater. Res, 31 (2001) 1-23

[51]K. Shimamura, T. Arima, K. Idemitsu, et al. Thermophysical properties of rareearth-stabilized zirconia and zirconate pyrochlores as surrogates for actinide-doped zirconia [J]. Int. J. Thermophys. 28 (2007) 1074-1084.

[52]M.P. van Dijk, K.J. de Vries, A.J. Burggraaf. Oxygen ion and mixed conductivity in compounds with the fluorite and pyrochlore structure [J]. J. Solid State Chem. 10 (1983) 913-920.

[53]J. R. Childress, C. L. Chien, M. Y. Zhou, et al. Lattice softening in nanometer-size iron particles [J]. Phys. Rev. B. 44 (1991) 11689-11696.

[54]J. Wu, X.Z. Wei, N.P. Padture, et al. Low-thermal-conductivity rare-earth zirconates for potential thermal-barrier-coating applications, J. Am. Ceram. Soc. 85 (2002) 3031-3035.

[55]M.J. Maloney, US Patent and Trademark Office (United Technologies Corporation, Hartford, CT), ((2001a.b) Pat. 6).

[56]G. Suresh, G. Seenivasan, M.V. Krishnaiah, et al. Investigation of the thermal conductivity of selected compounds of gadolinium and lanthanum, J. Nucl. Mater 249 (1997) 259-261.

[57]C. L. Wan, W. Zhang, Y. F. Wang, et al. Glass-like thermal conductivity in 
ytterbium-doped lanthanum zirconate pyrochlore [J]. Acta Mater. 58 (2010) 61666172.

[58]X. B. Li. Investigation of cold sprayed NiCoCrAlY bond coating [J]. Adv. Mater. Res. 79 (2009) 863-866.

[59]A. Ul-Hamid, H. Dafalla, F. Al-Yousef, et al. Microstructural Study of NiCrAlY Electrodeposits [J]. Prot. Met. Phys. Chem. Surf. 50 (2014) 679-687.

[60]G. Jin, Y. C. Fang, X. F. Cui, et al. Effect of YSZ fibers and carbon nanotubes on bonding strength and thermal cycling lifetime of $\mathrm{YSZ}-\mathrm{La}_{2} \mathrm{Zr}_{2} \mathrm{O}_{7}$ thermal barrier coatings [J]. Surf. Coat. Technol. 397 (2020) 125986-125996.

[61]L. Guo, Z. Yan, Z. H. Li, et al. $\mathrm{GdPO}_{4}$ as a novel candidate for thermal barrier coating applications at elevated temperatures [J]. Surf. Coat. Technol. 349 (2018) 400-406.

[62]Z. G. Liu, W. H. Zhang, J. H. Ouyang, et al. Novel double-ceramic-layer $\left(\mathrm{La}_{0.8} \mathrm{Eu}_{0.2}\right)_{2} \mathrm{Zr}_{2} \mathrm{O}_{7} / \mathrm{YSZ}$ thermal barrier coatings deposited by plasma spraying $[\mathrm{J}]$. Ceram. Int. 40 (2014) 11277-11282.

[63]A. C. Karaoglanli, K. M. Doleker, Y. Ozgurluk. Interface failure behavior of yttria stabilized zirconia (YSZ), $\mathrm{La}_{2} \mathrm{Zr}_{2} \mathrm{O}_{7}, \mathrm{Gd}_{2} \mathrm{Zr}_{2} \mathrm{O}_{7}, \mathrm{YSZ} / \mathrm{La}_{2} \mathrm{Zr}_{2} \mathrm{O}_{7}$ and $\mathrm{YSZ} / \mathrm{Gd}_{2} \mathrm{Zr}_{2} \mathrm{O}_{7}$ thermal barrier coatings (TBCs) in thermal cyclic exposure [J]. Mater. Charact. 159 (2020) 11072-11084. 


\section{Figure Captions}

Fig. 1. Crystal structure of $\mathrm{Gd}_{2} \mathrm{Zr}_{2} \mathrm{O}_{7}$

Fig. 2. Solid solution mode of $\mathrm{Sc}$ in $\mathrm{Gd}_{2} \mathrm{Zr}_{2} \mathrm{O}_{7}$ lattice with different doping contents

Fig. 3. The variations of lattice constants with the Sc content

Fig. 4. The variations of (a) Elastic constants $\mathrm{C}_{11}, \mathrm{C}_{12}, \mathrm{C}_{44}$ and (b) Bulk modulus $\mathrm{B}$, Shear modulus G and Young's modulus E with the Sc content

Fig. 5. The variations of Pugh's indicator $(\mathrm{G} / \mathrm{B})$ and Poisson ratios $(\sigma)$ with the Sc content

Fig. 6. The variation of Debye temperature $\Theta$ (a) and thermal conductivity (b) with the Sc content

Fig. 7. XRD patterns of Gd-Sc powders and coatings (a), and DSC curve of Gd-Sc powders (b)

Fig. 8. Cross-section microstructures of the Gd-Sc TBC (a) and the Gd-Sc/YSZ DCL $\mathrm{TBC}(\mathrm{b})$

Fig. 9. XRD patterns of Gd-Sc coatings after different heat treatment time

Fig. 10. Surface morphologies of Gd-Sc coatings after heat treatment at $1400{ }^{\circ} \mathrm{C}$ for (a) $20 \mathrm{~h}$, (b) $50 \mathrm{~h}$, (c) $100 \mathrm{~h}$ and (d) $200 \mathrm{~h}$

Fig. 11. Fracture surface morphologies of Gd-Sc coatings after heat treatment at $1400{ }^{\circ} \mathrm{C}$ for (a) $20 \mathrm{~h}$, (b) $50 \mathrm{~h}$, (c) $100 \mathrm{~h}$ and (d) $200 \mathrm{~h}$

Fig. 12. Macroscopic morphologies evolution of Gd-Sc TBCs ( $a$ and b) and Gd-Sc/YSZ DCL TBCs (c and d) during thermal cycling tests

Fig. 13. XRD patterns of Gd-Sc TBCs (a) and Gd-Sc/YSZ DCL TBCs (b) after thermal 
cycling tests

Fig. 14. Cross-sectional microstructures of regions A (a) and B (b) of Gd-Sc TBCs after 75 thermal cycles

Fig. 15. Cross-sectional microstructures of regions C (a) and D (b) of Gd-Sc/YSZ DCL TBCs after 215 thermal cycles 
Table 1

The plasma spray parameters of Gd-Sc/YSZ coatings

\begin{tabular}{ccc}
\hline Parameter & Gd-Sc & YSZ \\
\hline Current $(\mathrm{A})$ & 760 & 800 \\
Power $(\mathrm{KW})$ & 32 & 30 \\
Plasma gas, Ar/ $\mathrm{H}_{2}(\mathrm{SCFH})$ & $80 / 4$ & $80 / 4$ \\
Carrier gas, $\mathrm{Ar}(\mathrm{SCFH})$ & 8 & 8 \\
Spray distance $(\mathrm{mm})$ & 100 & 100 \\
\hline
\end{tabular}

Table 2

Composition (wt. \%) of NiCoCrAlY and Ni-based superalloy (DZ125)

\begin{tabular}{cccccccc}
\hline & $\mathrm{Ni}$ & $\mathrm{Co}$ & $\mathrm{Cr}$ & $\mathrm{Al}$ & $\mathrm{Y}$ & $\mathrm{W}$ & Others \\
\hline NiCoCrAlY & 42.5 & 22.6 & 23.4 & 10 & 1.5 & - & - \\
DZ125 & 59.6 & 10.5 & 9.1 & 5.2 & - & 7 & 9.2 \\
\hline
\end{tabular}

Table 3

The structural parameters of $\mathrm{Gd}_{2} \mathrm{Zr}_{2} \mathrm{O}_{7}$

\begin{tabular}{cccc}
\hline & $a_{0}$ & $\mathrm{x}_{\mathrm{O}-48 \mathrm{f}}$ & $\rho\left(\mathrm{g} / \mathrm{cm}^{3}\right)$ \\
\hline $\mathrm{Gd}_{2} \mathrm{Zr}_{2} \mathrm{O}_{7}$ & 10.600 & 0.3386 & 6.79 \\
$\mathrm{Cal} .[37]$ & 10.682 & 0.338 & 6.629 \\
Cal. [27] & 10.452 & 0.342 & \\
Cal. [38] & 10.66 & 0.339 & \\
Exp. [39] & 10.54 & 0.344 & $6.8[40]$ \\
\hline
\end{tabular}


Table 4

Lattice constants and formation energy calculations of Sc-doped $\mathrm{Gd}_{2} \mathrm{Zr}_{2} \mathrm{O}_{7}$

\begin{tabular}{cccc}
\hline & Sc content & $a_{0}$ & $\mathrm{E}_{\mathrm{f}}$ \\
\hline $\mathrm{Gd}_{\mathrm{Sc} \text {-sub }}$ & $6.25 \%$ & 10.581 & 1.269 \\
$\mathrm{Gd}_{\text {Sc-inter }}$ & $5.88 \%$ & 10.646 & 0.141 \\
$\mathrm{Gd}_{\mathrm{Sc}-2 \text {-inter }}$ & $11.11 \%$ & 10.663 & 0.659 \\
$\mathrm{Gd}_{\text {Sc-2-inter+sub }}$ & $11.76 \%$ & 10.632 & 0.745 \\
$\mathrm{Gd}_{\mathrm{Sc}-3 \text {-inter }}$ & $15.79 \%$ & 10.758 & 3.347 \\
$\mathrm{Gd}_{\text {Sc-3-2inter+1-sub }}$ & $16.67 \%$ & 10.647 & 0.953 \\
$\mathrm{Gd}_{\text {Sc-4-2-inter+2-sub }}$ & $22.22 \%$ & 10.623 & 1.621 \\
\hline
\end{tabular}

Table 5

Elastic constant and elastic modulus of Sc-doped $\mathrm{Gd}_{2} \mathrm{Zr}_{2} \mathrm{O}_{7}$

\begin{tabular}{ccccccc}
\hline & $\mathrm{C}_{11}$ & $\mathrm{C}_{12}$ & $\mathrm{C}_{44}$ & $\mathrm{~B}$ & $\mathrm{G}$ & $\mathrm{E}$ \\
\hline $\mathrm{Gd}_{2} \mathrm{Zr}_{2} \mathrm{O}_{7}$ & 296.521 & 101.943 & 86.824 & 166.803 & 90.869 & 230.712 \\
$\mathrm{Cal} .[27]$ & 324.7 & 125.3 & 94 & 191.8 & 96.2 & 247.3 \\
$\mathrm{Cal} .[32]$ & 277 & 110 & 52 & 165 & 63 & 214 \\
Exp. [49] & - & - & - & 174 & 93 & 236 \\
Exp. [50] & - & - & - & 153 & 80 & 205 \\
Gd & 263.328 & 69.894 & 48.769 & 123.007 & 66.713 & 169.497 \\
$\mathrm{Gd}_{\text {Sc-2-inter }}$ & 285.407 & 81.656 & 55.201 & 147.880 & 69.716 & 180.745 \\
$\mathrm{Gd}_{\text {Sc-3- }}$ & 281.431 & 99.205 & 58.998 & 154.205 & 62.964 & 166.263 \\
2inter+1-sub & & & & & & \\
$\mathrm{Gd}_{\text {Sc-4-2- }}$ & 273.801 & 86.689 & 53.527 & 140.88 & 60.089 & 157.827 \\
inter+2-sub & & & & & &
\end{tabular}


Table 6

Pugh's indicator(G/B) and Poisson ratios $(\sigma)$ of Sc-doped $\mathrm{Gd}_{2} \mathrm{Zr}_{2} \mathrm{O}_{7}$

\begin{tabular}{ccc}
\hline & $\mathrm{G} / \mathrm{B}$ & $\sigma$ \\
\hline $\mathrm{Gd}_{2} \mathrm{Zr}_{2} \mathrm{O}_{7}$ & 0.545 & 0.269 \\
$\mathrm{Cal} .[26]$ & 0.500 & 0.285 \\
Exp. [49] & 0.530 & 0.273 \\
$\mathrm{Gd}_{\text {Sc-inter }}$ & 0.542 & 0.270 \\
$\mathrm{Gd}_{\text {Sc-2-inter }}$ & 0.471 & 0.296 \\
$\mathrm{Gd}_{\text {Sc-3-2inter+1-sub }}$ & 0.408 & 0.32 \\
$\mathrm{Gd}_{\text {Sc-4-2-inter+2-sub }}$ & 0.427 & 0.313 \\
\hline
\end{tabular}

Table 7

Thermophysical properties of Sc-doped $\mathrm{Gd}_{2} \mathrm{Zr}_{2} \mathrm{O}_{7}$

\begin{tabular}{|c|c|c|c|c|c|c|}
\hline & $\mathrm{V}_{1}$ & $\mathrm{~V}_{\mathrm{t}}$ & $\mathrm{V}_{\mathrm{m}}$ & $\Theta$ & $\mathrm{k}_{\text {Clarke }}$ & $\mathrm{k}_{\text {Cahill }}$ \\
\hline $\mathrm{GZO}$ & 6512.44 & 3658.179 & 4070.692 & 508.506 & 1.23 & 1.35 \\
\hline Cal. [26] & & & 4108.0 & 520.7 & 1.29 & 1.42 \\
\hline Exp. & & & & $513.4[49]$ & \multicolumn{2}{|c|}{$1.0-1.6[52-54]$} \\
\hline $\mathrm{Gd}_{\text {Sc-inter }}$ & 5595.406 & 3139.157 & 3493.509 & 436.277 & 1.06 & 1.16 \\
\hline $\mathrm{Gd}_{\mathrm{Sc}-2 \text {-inter }}$ & 5955.415 & 3204.201 & 3577.345 & 447.505 & 1.17 & 1.21 \\
\hline $\begin{array}{c}\mathrm{Gd}_{\mathrm{Sc}-3-} \\
\text { 2inter+1-sub }\end{array}$ & 5968.192 & 3068.724 & 3436.649 & 430.97 & 1.06 & 1.20 \\
\hline $\begin{array}{l}\mathrm{Gd}_{\mathrm{Sc}-4-2-} \\
\text { inter+2-sub }\end{array}$ & 5809.301 & 3029.188 & 3389.289 & 425.403 & 1.05 & 1.17 \\
\hline
\end{tabular}


Figures

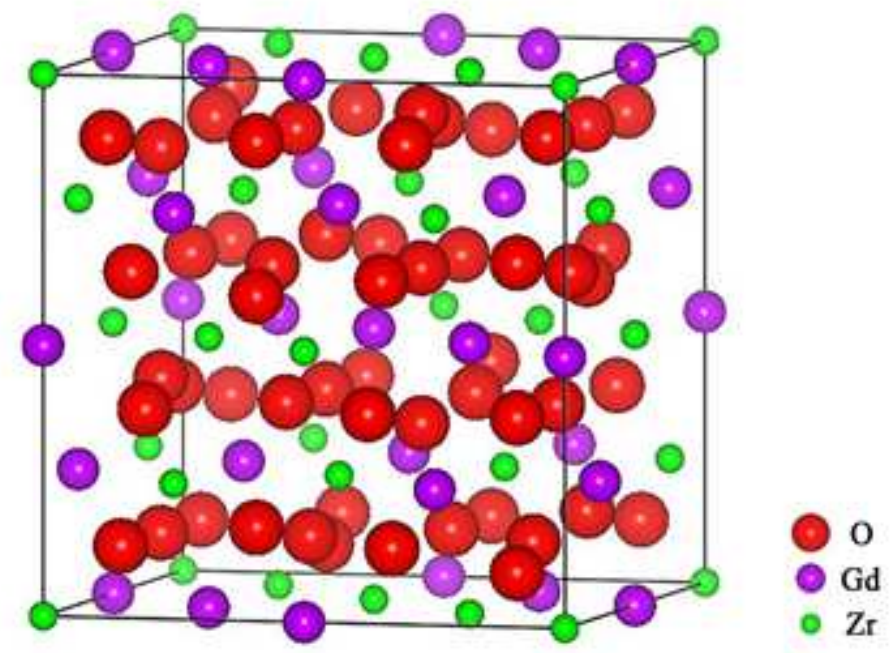

Figure 1

Crystal structure of Gd2Zr2O7 


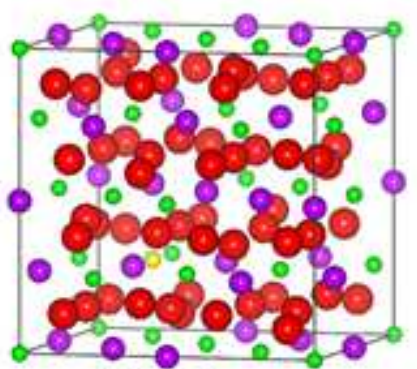

(a) $\mathrm{Gd}_{\text {Se-1-inter }}$

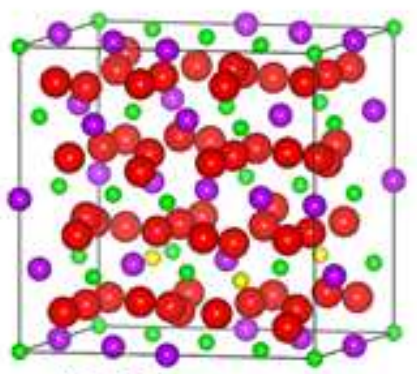

(c) $\mathrm{Gd}_{\mathrm{Sc-2-1-inter-1-sub}}$

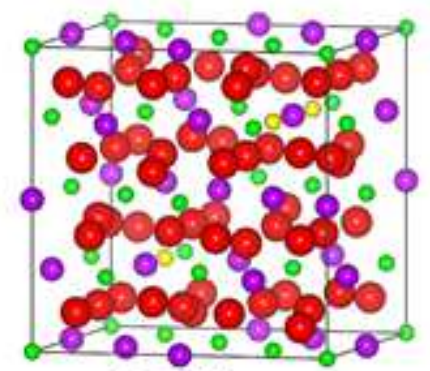

(e) $\mathrm{Gd}_{\mathrm{Sc}-3 \text {-inter }}$

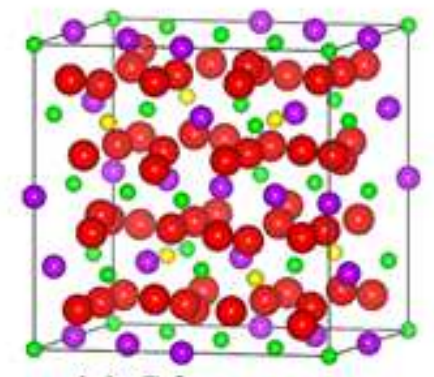

(g) $\mathrm{Gd}_{\mathrm{Sc}-4-2-\text { inter-2-sub }}$

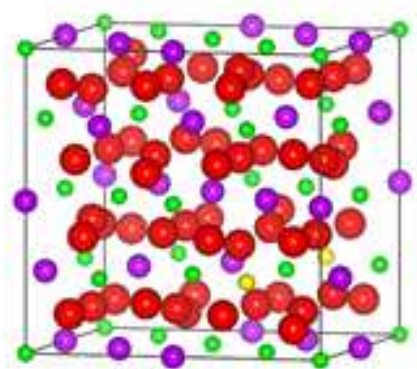

(b) $\mathrm{Gd}_{\mathrm{Se-1- \text {sub }}}$

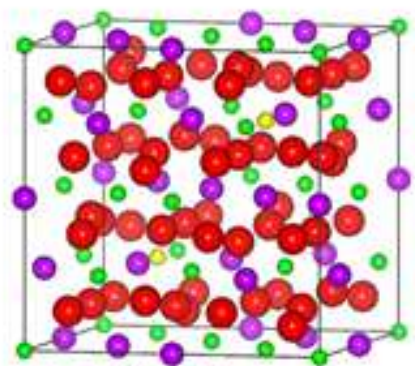

(d) $\mathrm{Gd}_{\text {Sc-2-inter }}$

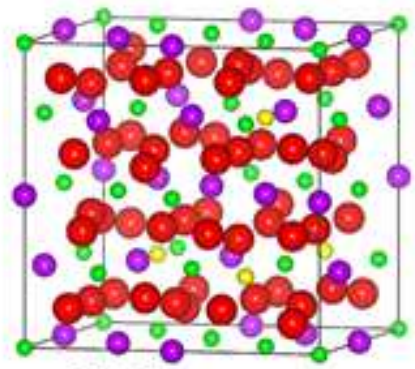

(f) $\mathrm{Gd}_{\mathrm{Se}-3-2 \text {-inter-1-sub }}$

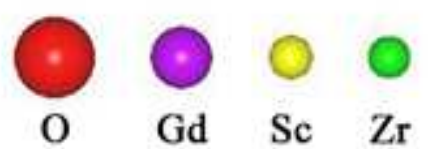

Figure 2

Solid solution mode of Sc in Gd2Zr2O7 lattice with different doping contents 


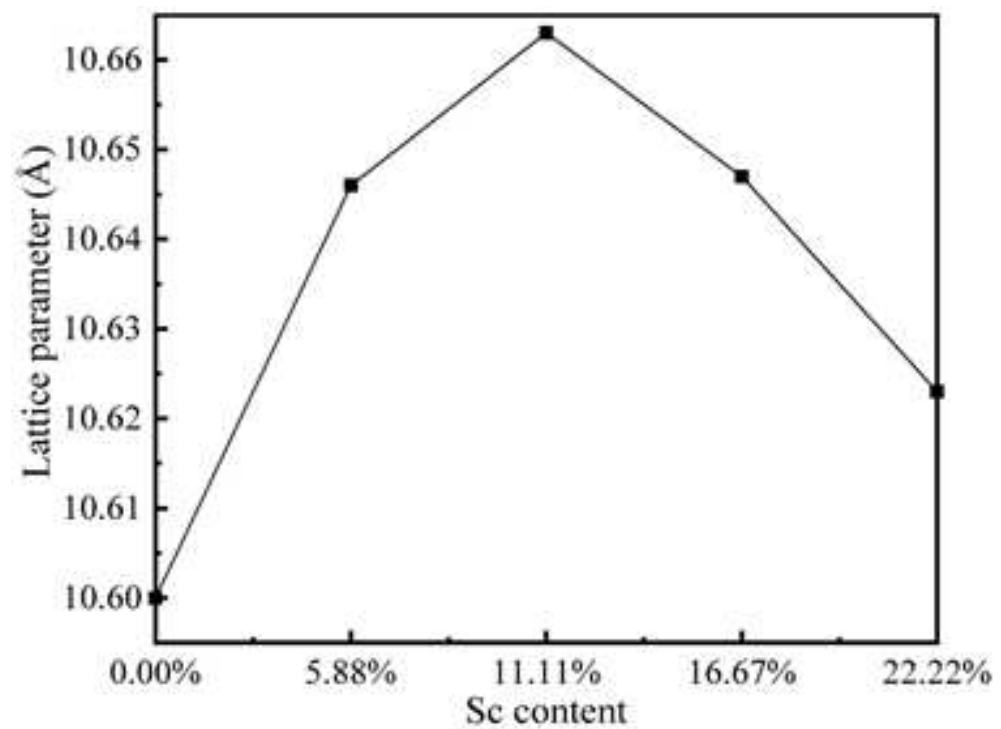

Figure 3

The variations of lattice constants with the Sc content 

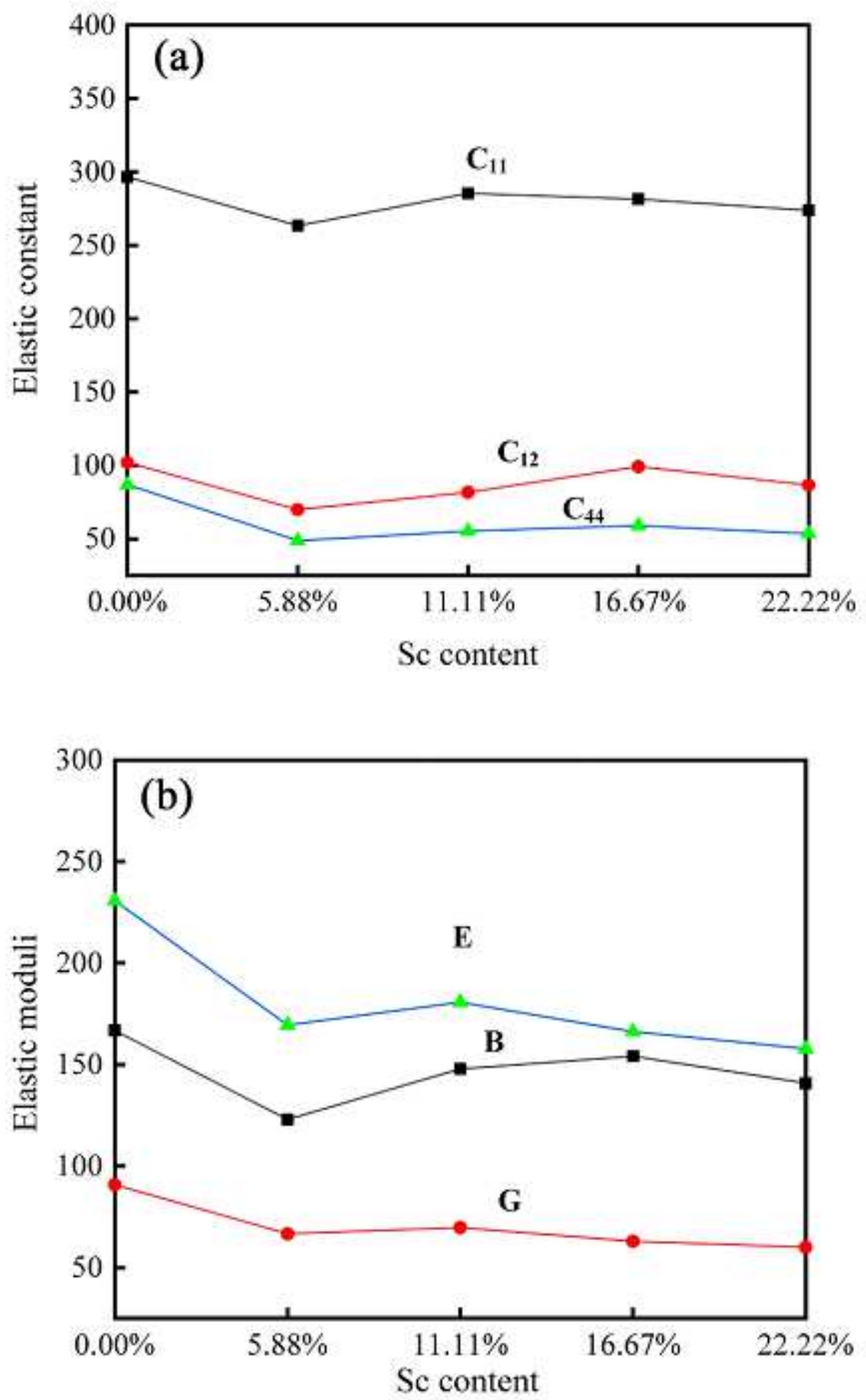

Figure 4

The variations of (a) Elastic constants $\mathrm{C} 11, \mathrm{C} 12, \mathrm{C} 44$ and (b) Bulk modulus B, Shear modulus $\mathrm{G}$ and Young's modulus E with the Sc content 


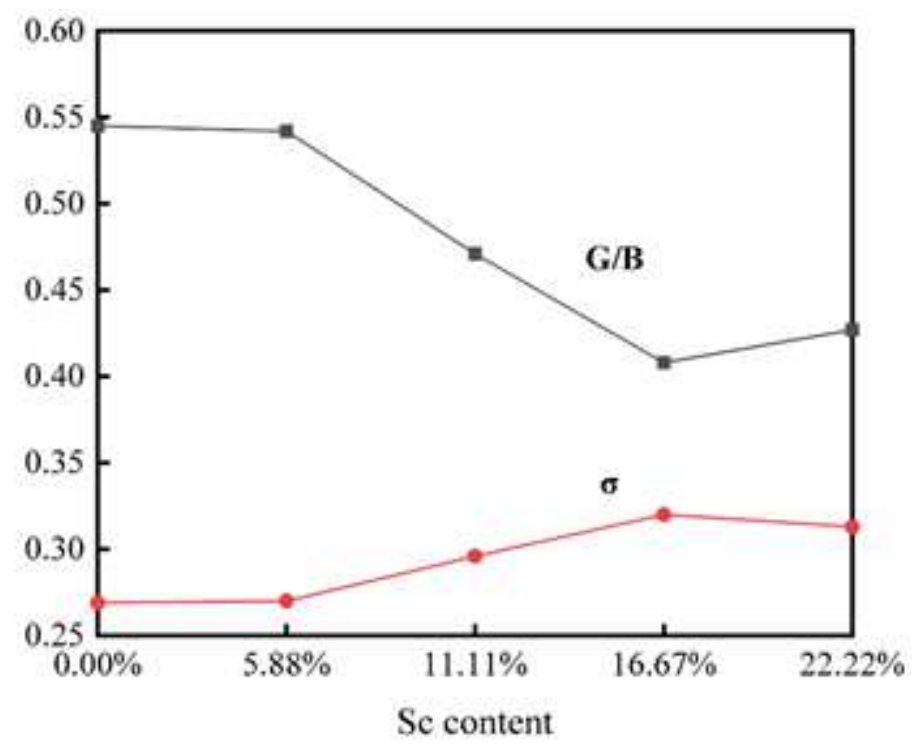

Figure 5

The variations of Pugh's indicator(G/B) and Poisson ratios ( $\sigma)$ with the Sc content 

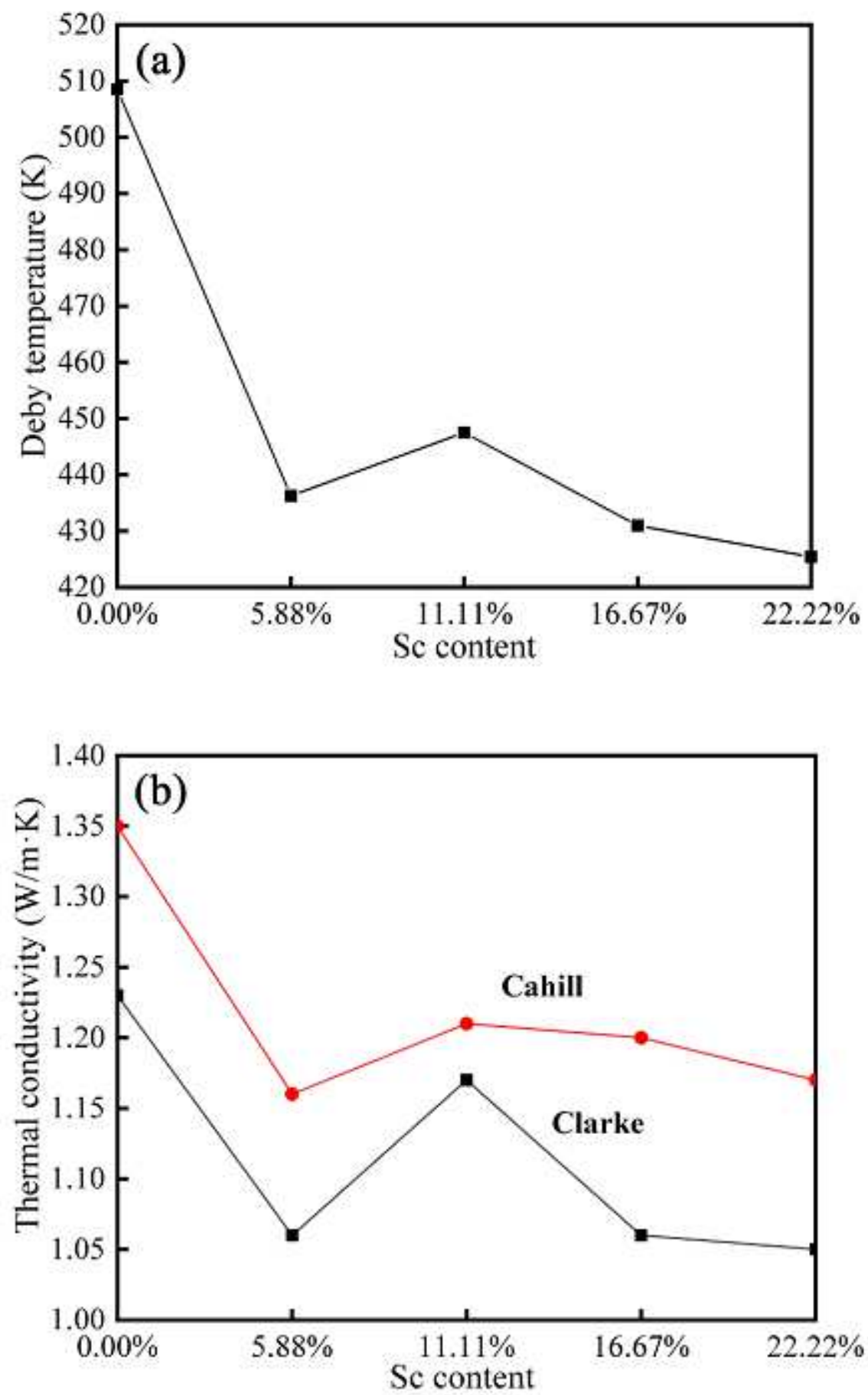

Figure 6

The variation of Debye temperature $\Theta(a)$ and thermal conductivity (b) with the Sc content 

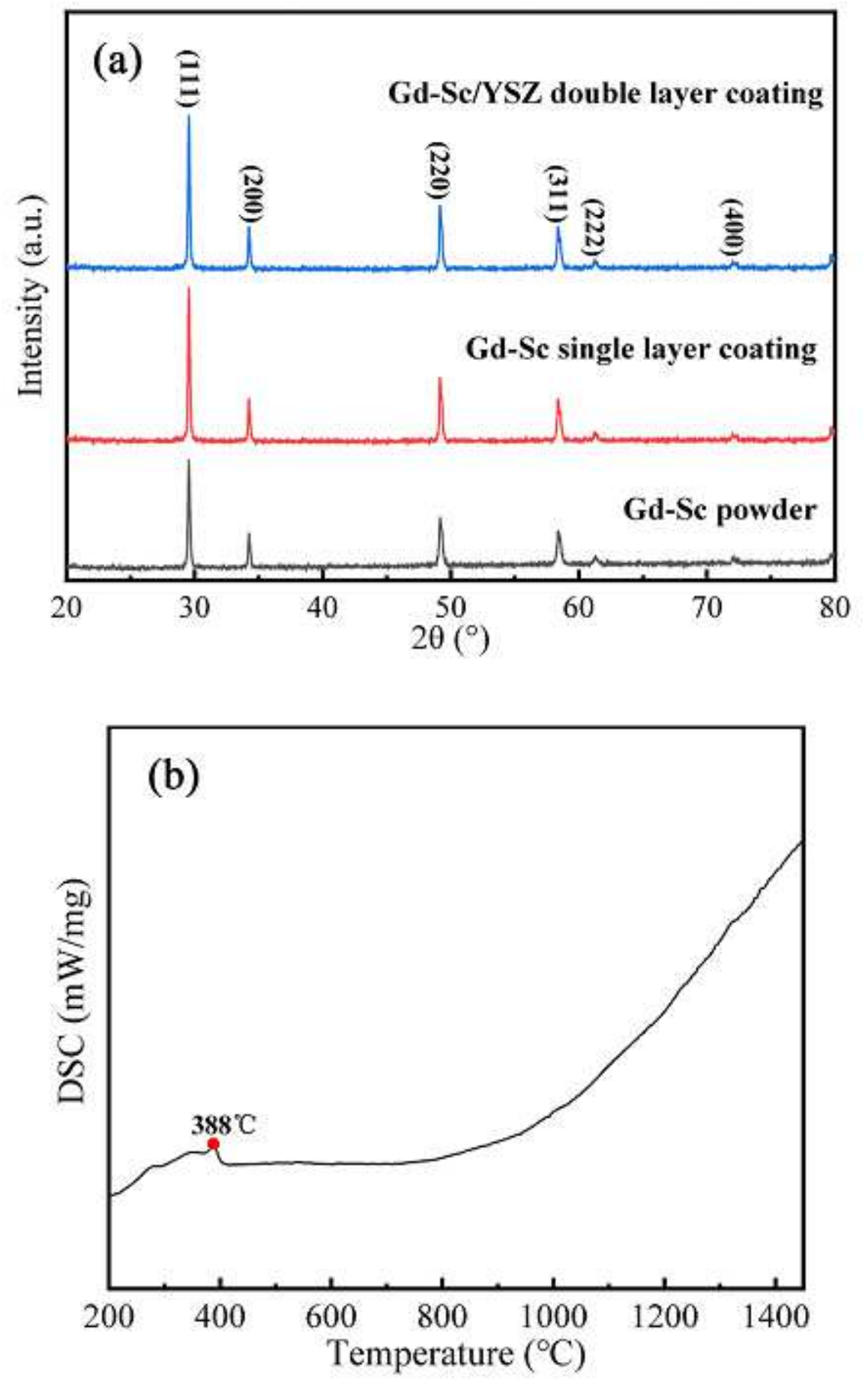

Figure 7

XRD patterns of Gd-Sc powders and coatings (a), and DSC curve of Gd-Sc powders (b) 

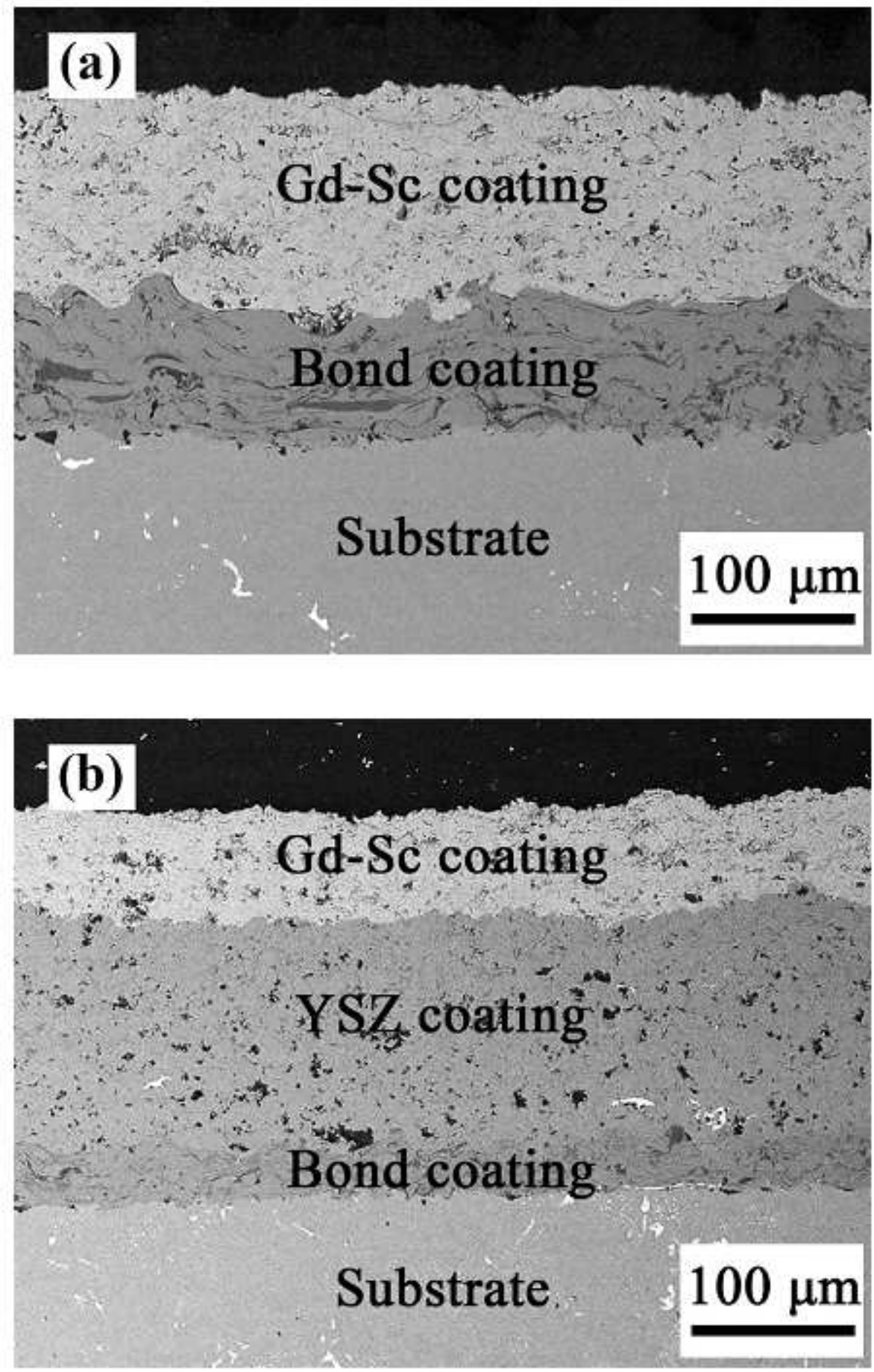

Figure 8

Cross-section microstructures of the Gd-Sc TBC (a) and the Gd-Sc/YSZ DCL TBC (b) 


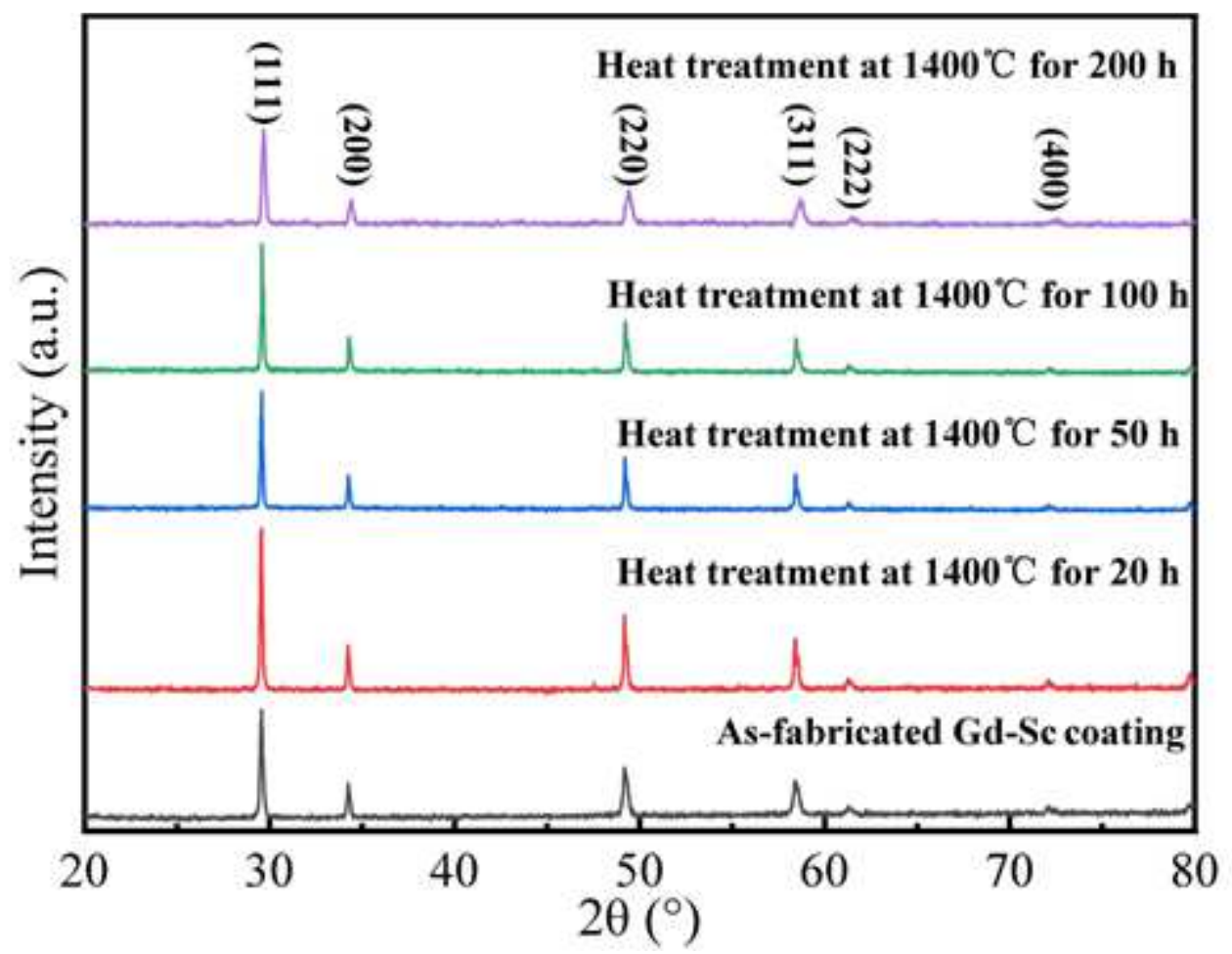

Figure 9

XRD patterns of Gd-Sc coatings after different heat treatment time 

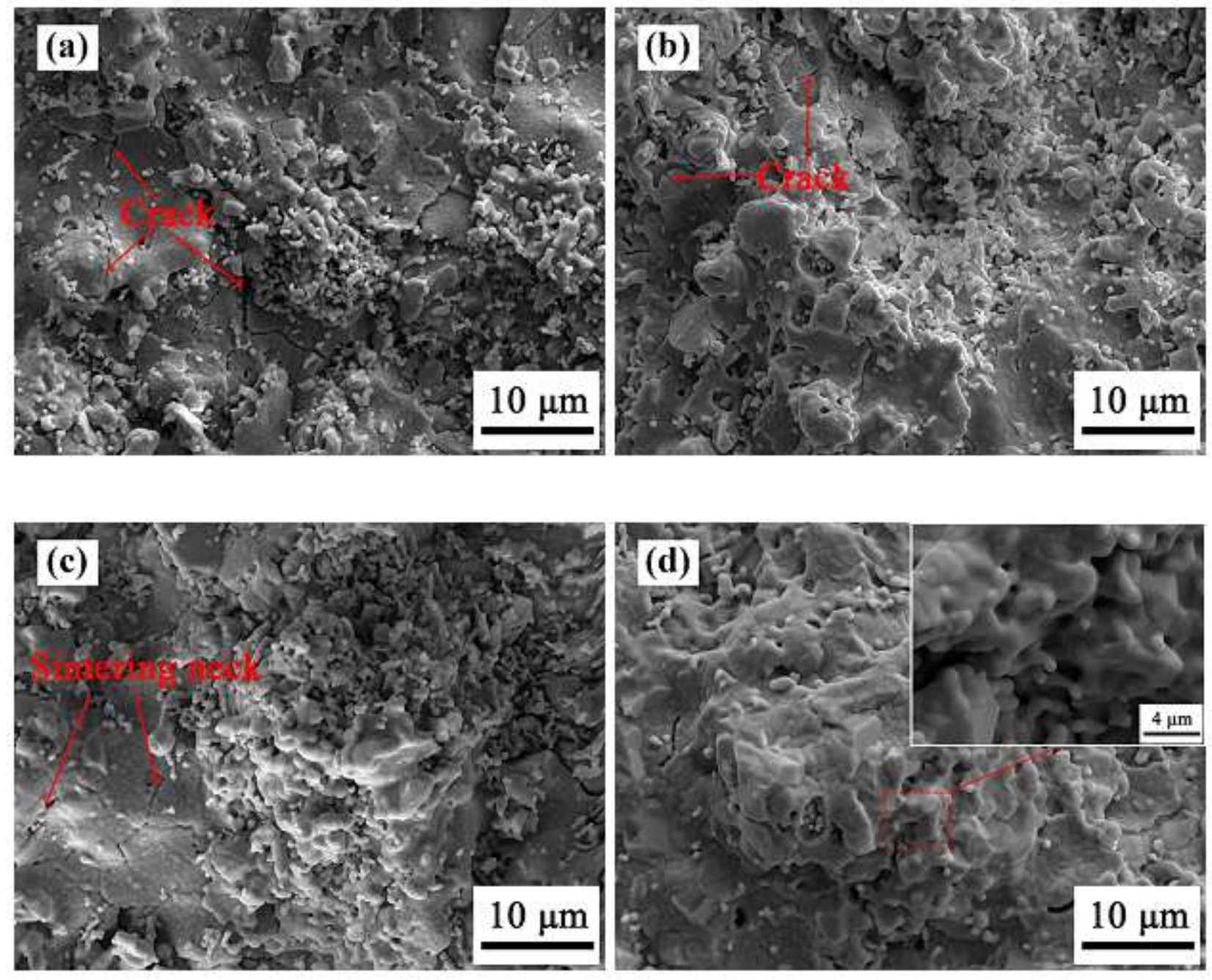

Figure 10

Surface morphologies of Gd-Sc coatings after heat treatment at $1400 \otimes$ for (a) $20 \mathrm{~h}$, (b) $50 \mathrm{~h}$, (c) $100 \mathrm{~h}$ and (d) $200 \mathrm{~h}$ 

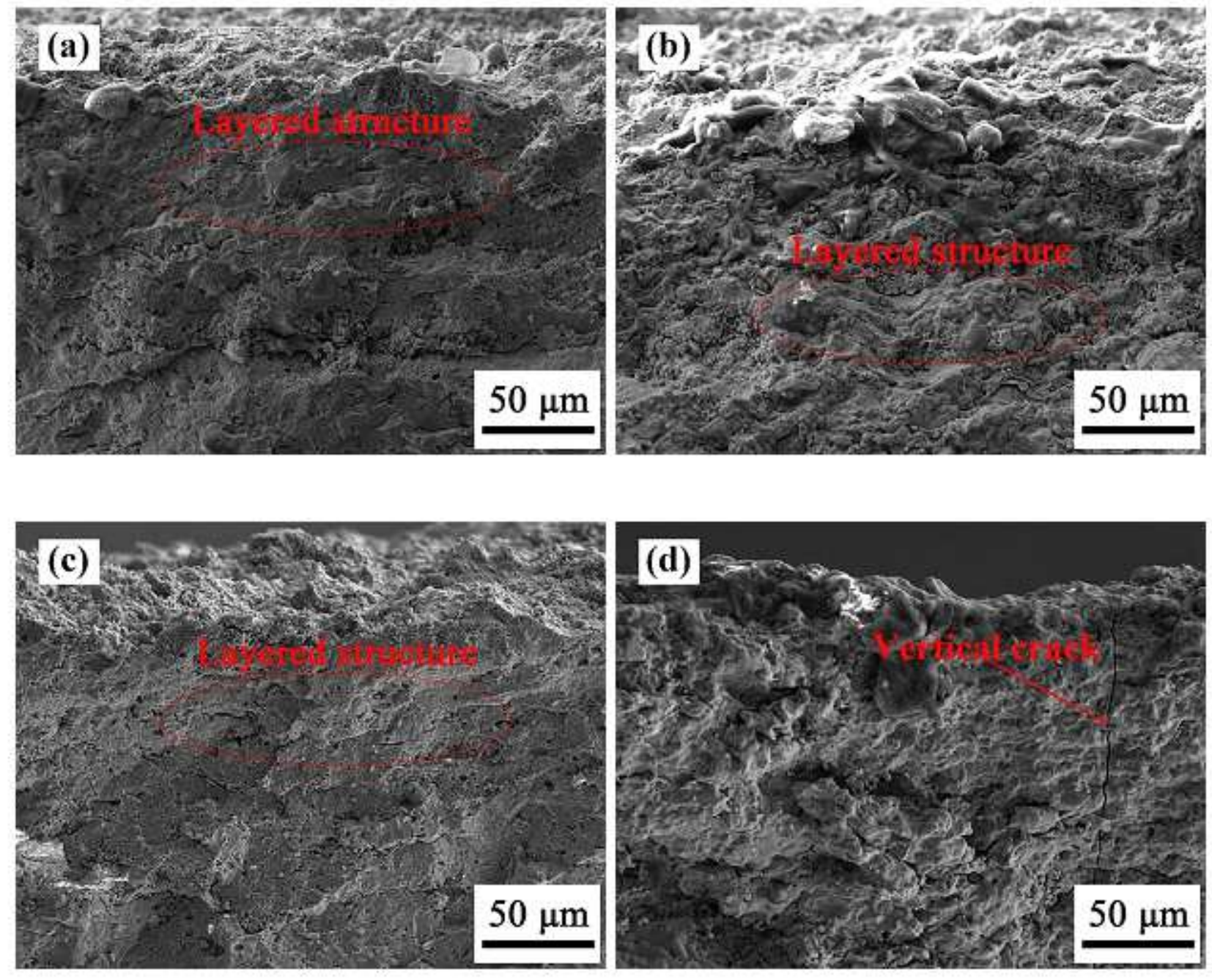

\section{Figure 11}

Fracture surface morphologies of Gd-Sc coatings after heat treatment at $1400 \otimes$ for (a) $20 \mathrm{~h}$, (b) $50 \mathrm{~h}$, (c) $100 \mathrm{~h}$ and $(\mathrm{d}) 200 \mathrm{~h}$ 

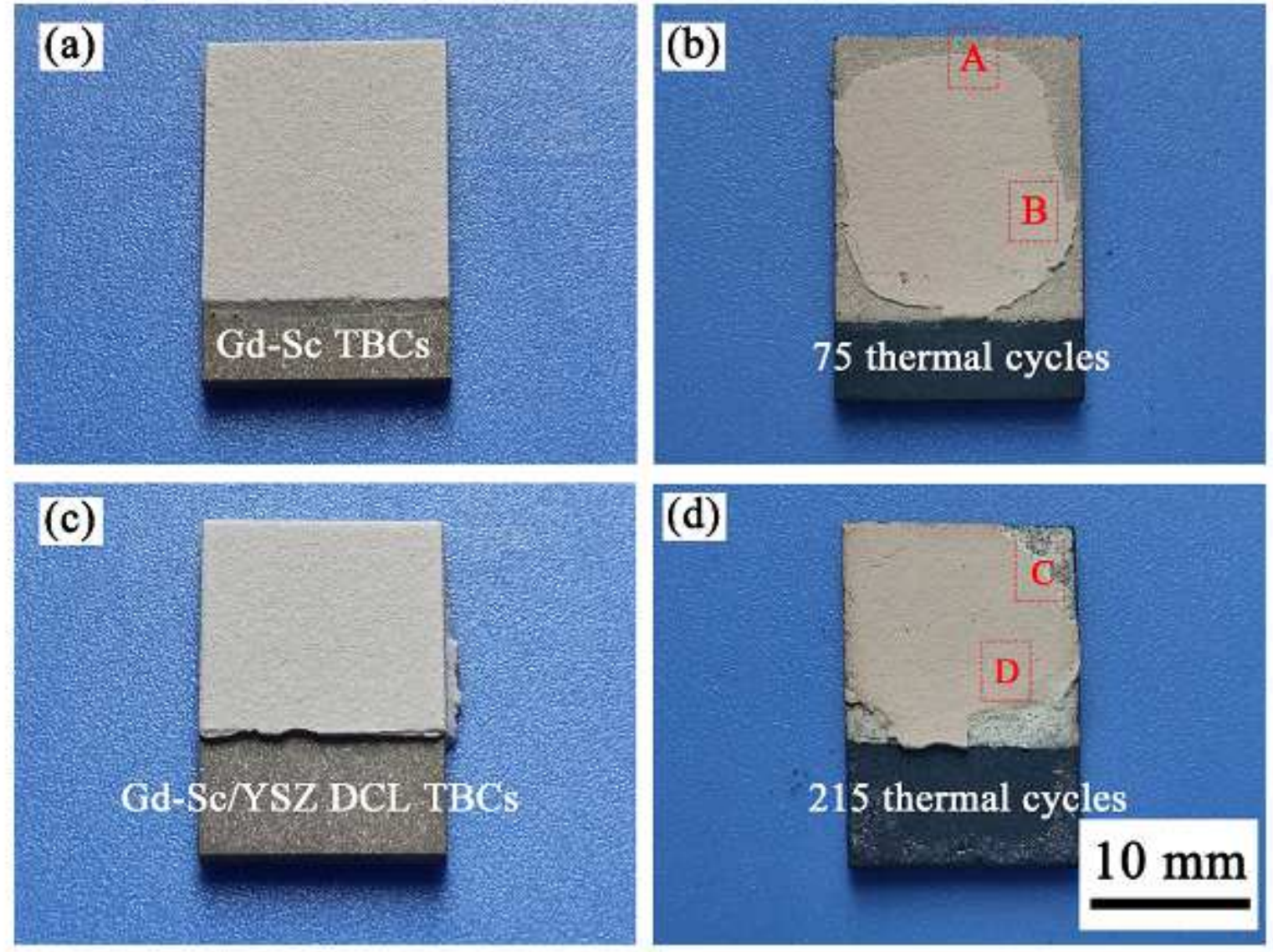

Figure 12

Macroscopic morphologies evolution of Gd-Sc TBCs (a and b) and Gd-Sc/YSZ DCL TBCs (c and d) during thermal cycling tests 

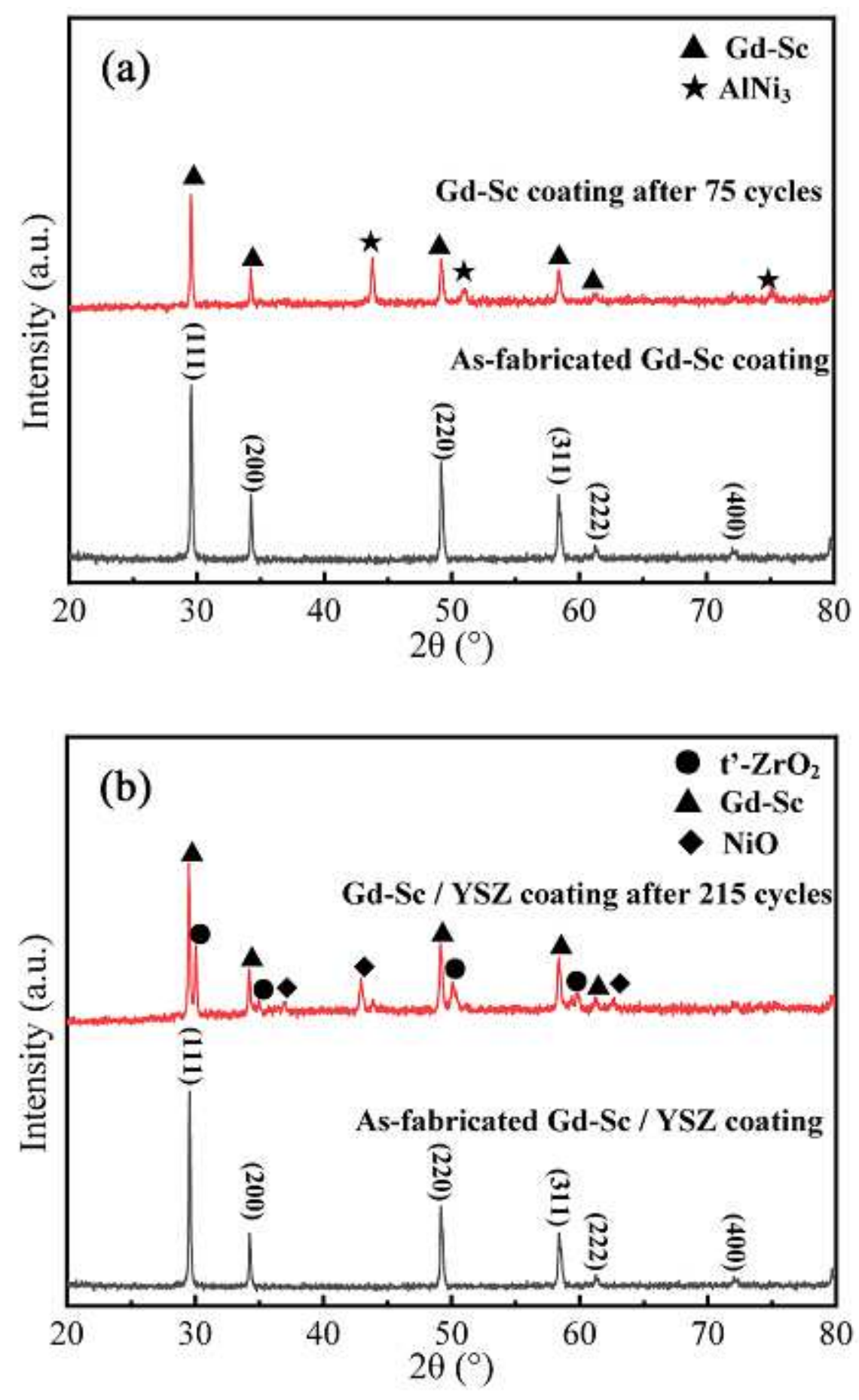

Figure 13

XRD patterns of Gd-Sc TBCs (a) and Gd-Sc/YSZ DCL TBCs (b) after thermal cycling tests 

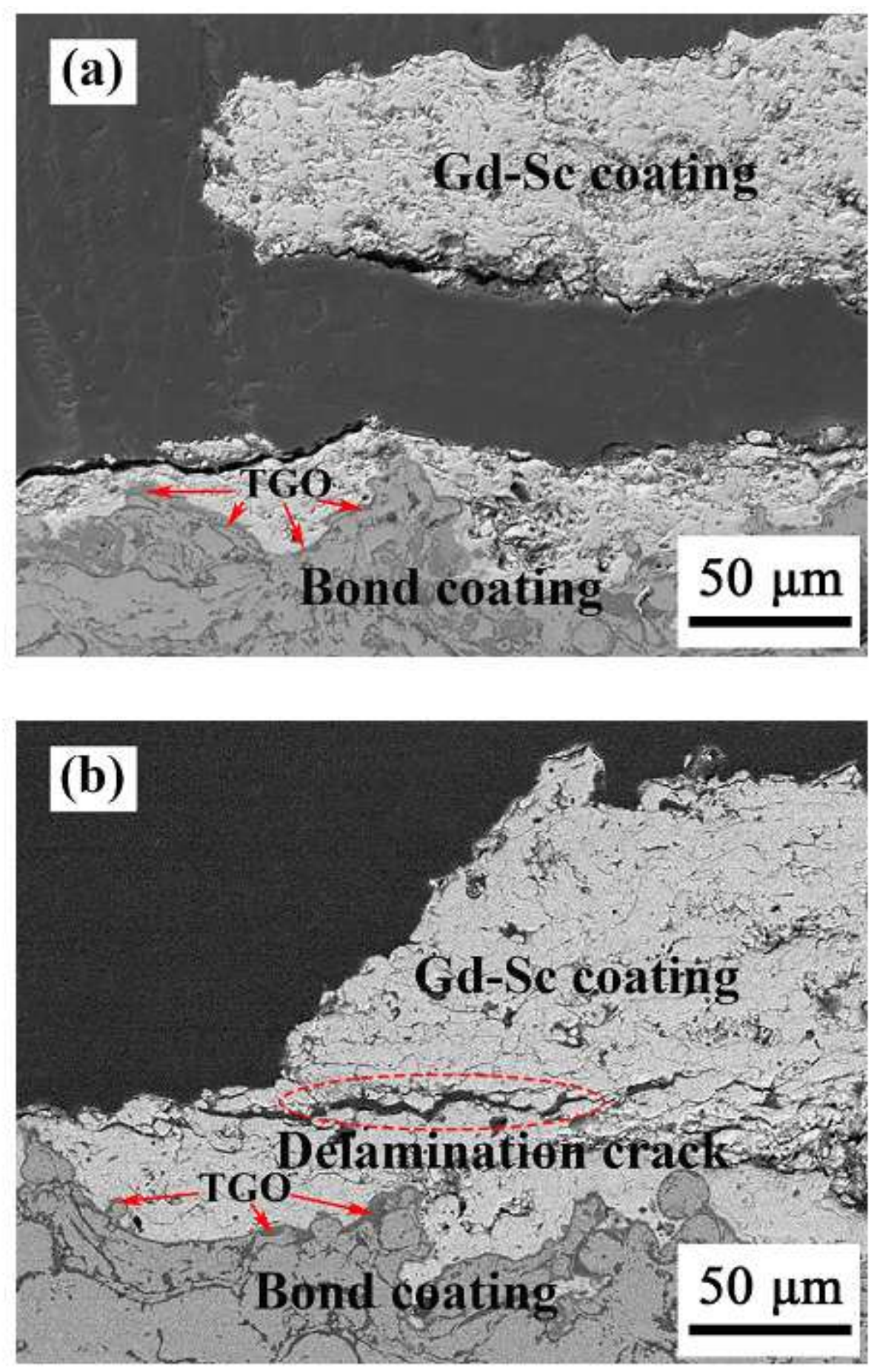

Figure 14

Cross-sectional microstructures of regions A (a) and B (b) of Gd-Sc TBCs after 75 thermal cycles 

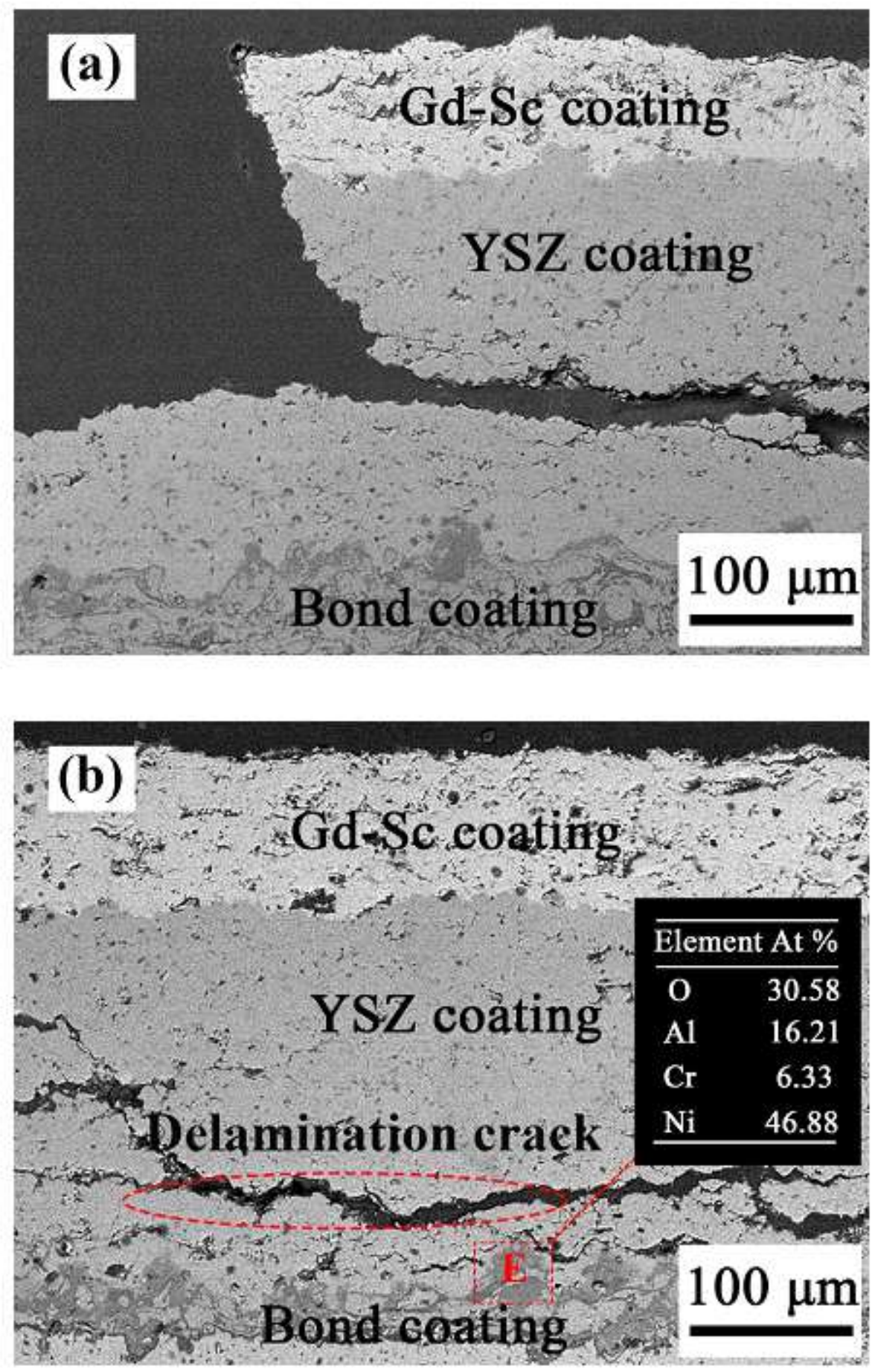

Figure 15

Cross-sectional microstructures of regions C (a) and D (b) of Gd-Sc/YSZ DCL TBCs after 215 thermal cycles 